\title{
Indoleamine 2,3-dioxygenase 1 (IDO1) inhibitors in clinical trials for cancer immunotherapy
}

\author{
Kai Tang ${ }^{1 \dagger}$, Ya-Hong $\mathrm{Wu}^{2+}$, Yihui Song ${ }^{1}$ and Bin $\mathrm{Yu}^{1,3^{*}}$ (D)
}

\begin{abstract}
Indoleamine 2,3-dioxygenase 1 (IDO1) is a heme enzyme that catalyzes the oxidation of L-tryptophan. Functionally, IDO1 has played a pivotal role in cancer immune escape via catalyzing the initial step of the kynurenine pathway, and overexpression of IDO1 is also associated with poor prognosis in various cancers. Currently, several small-molecule candidates and peptide vaccines are currently being assessed in clinical trials. Furthermore, the "proteolysis targeting chimera" (PROTAC) technology has also been successfully used in the development of IDO1 degraders, providing novel therapeutics for cancers. Herein, we review the biological functions of IDO1, structural biology and also extensively summarize medicinal chemistry strategies for the development of IDO1 inhibitors in clinical trials. The emerging PROTAC-based IDO1 degraders are also highlighted. This review may provide a comprehensive and updated overview on IDO1 inhibitors and their therapeutic potentials.
\end{abstract}

Keywords: Immune escape, IDO1 inhibitors, PROTAC degraders, Cancer therapy

\section{Introduction}

Normally, the immune system recognizes and obliterates foreign invaders including tumor cells in the tumor microenvironment [1]. However, tumor cells could avoid destruction by the immune system through multiple local immunosuppression mechanisms, which frequently contribute to the survival of tumor cells in the different stages of the anti-tumor immune response [2-4]. By reinstating the cancer-immunity cycle, cancer immunotherapy could strengthen the anti-tumor immune response, and restore the functions of the immune system to distinguish and eliminate tumor cells [5]. Currently, many immunotherapy therapies, including checkpoint inhibitors [6], monoclonal antibodies (mAbs) [7] and vaccines

\footnotetext{
*Correspondence: yubin@zzu.edu.cn

${ }^{\dagger}$ Kai Tang and Ya-Hong Wu have contributed equally to this work ${ }^{1}$ School of Pharmaceutical Sciences and Key Laboratory of Advanced Drug Preparation Technologies, Ministry of Education, Zhengzhou University, Zhengzhou 450001, China

Full list of author information is available at the end of the article
}

[8], are being developed for treating various cancers, especially melanoma, breast cancer and non-small cell lung cancer (NSCLC), etc. It has been widely recognized that combination of these novel therapies with standard chemo or radiotherapy could be an effective approach to overcome tumor-induced immunosuppression in clinic settings [9-11].

Previous studies have revealed that the kynurenine (Kyn) pathway is involved in tumor-associated immunosuppression [12]. In this pathway, three heme-containing enzymes including indoleamine 2,3-dioxygenase 1 (IDO1), indoleamine 2,3-dioxygenase 2 (IDO2) [13], and tryptophan 2,3-dioxygenase (TDO) [14] could catalyze the rate-limiting step of tryptophan (Trp) metabolism. Among them, IDO1 has played a pivotal role in this pathway [15-17]. IDO1 catalyzes the initial oxidation of $L$-tryptophan $(L$-Trp) and induces the accumulation of kynurenine metabolites [18-20], which lead to the suppression of T-cell and are responsible for tumor cells to escape the monitoring and clearance of the immune original author(s) and the source, provide a link to the Creative Commons licence, and indicate if changes were made. The images or other third party material in this article are included in the article's Creative Commons licence, unless indicated otherwise in a credit line to the material. If material is not included in the article's Creative Commons licence and your intended use is not permitted by statutory regulation or exceeds the permitted use, you will need to obtain permission directly from the copyright holder. To view a copy of this licence, visit http://creativecommons.org/licenses/by/4.0/. The Creative Commons Public Domain Dedication waiver (http://creativeco mmons.org/publicdomain/zero/1.0/) applies to the data made available in this article, unless otherwise stated in a credit line to the data. 
system [15]. Preclinical studies also support that IDO1 overexpression is associated with poor prognosis in the majority of cancers [21]. Over the past decade, intense efforts have been made to developing IDO1 inhibitors, and numerous small-molecule IDO1 inhibitors have been reported, some of them such as Epacadostat [22], BMS-986205 [23], Indoximod [24, 25] and PF-06840003 [26], etc., are currently being studied in clinical trials (Fig. 1). In addition, the "proteolysis targeting chimera" (PROTAC) technique has also been employed to design PROTAC-based IDO1 degraders, which show promise for cancer immunotherapy [27]. In this review, we aim to provide a timely and updated summary on the structural biology and biological functions of IDO1 as well as cancer immunotherapy of IDO1 inhibitors in clinical trials. Emphasis will be placed on the IDO1 inhibitors and peptide vaccines in clinical trials as well as the medicinal chemistry strategies for the development of IDO1 inhibitors. The recently reported PROTAC degraders, limitations and challenges of IDO1 inhibitors for cancer immunotherapy are also discussed.

\section{Biological functions of IDO1}

The rate-limiting enzyme in the Kyn pathway of Trp metabolism

The Kyn is an important metabolic pathway of Trp, which normally degrades Trp and generates corresponding catabolites. Different catabolites, involved in the formation of the immunosuppressive environment, are closely related to various diseases $[28,29]$. As the first and ratelimiting step in the Kyn pathway of Trp decomposition (Fig. 2), IDO1 plays a key role in catalyzing the oxidative cleavage of Trp and regulating the level of Trp as well as corresponding metabolites in the body [30]. In the Kyn pathway, the pyrrole ring of $L$-Trp is catalytically oxidized by IDO1 to give $N$-formyl kynurenine, which is then converted to $L$-Kyn in the presence of kynurenine formamidase. Anthranilic acid is generated from $L-K y n$ in the presence of kynureninase and further converted to 3-hydroxyanthranilic acid by kynurenine-3-monooxygenase, finally generating three metabolites including 2-amino-muconic acid, picolinic acid, and quinolinic acid. Quinolinic acid subsequently activates the generation of nicotinamide adenine dinucleotide $\left(\mathrm{NAD}^{+}\right)$in the presence of phosphoribosyl-transferase.

\section{Expression, function of IDO1 and its relationship with tumor immune escape}

IDO1 is an intracellular enzyme (principally in the cytosolic and perinuclear regions) to catalyze the conversion of $L$-Trp into Kyn. In normal physiological conditions, IDO1 is not expressed in many cell types and mainly expressed in mucosal tissues, placenta, eye, pancreas, and some immune cell subsets (some DC subsets, eosinophils) [28].

Studies have shown that relative to IDO2 and TDO, IDO1 has lower substrate specificity to catabolize Trp, and is associated with poor survival of various cancer<smiles>NS(=O)(=O)NCCCNc1nonc1/C(=N\O)Nc1ccc(F)c(Br)c1</smiles>

Epacadostat (INCB24360, 1)<smiles>Cn1cc(CC(N)C(=O)O)c2ccccc21</smiles>

Indoximod (5)<smiles>CC(C(=O)Nc1ccc(Cl)cc1)[C@H]1CC[C@H](c2ccnc3ccc(F)cc32)CC1</smiles>

BMS-986205 (2)<smiles>CCOC(=O)C(Cc1cn(C)c2ccccc12)NC(=O)C(N)CC(C)C</smiles>

NLG802 (Indoximod prodrug, 6)<smiles>O=C1CC(c2c[nH]c3ccc(F)cc23)C(=O)N1</smiles>

PF-06840003 (3)<smiles>O[C@H]1CC[C@@H](CC[C@H]2c3c(F)cccc3-c3cncn32)CC1</smiles>

Navoximod (4)<smiles>C[C@H](NC(=O)c1ccc(F)cc1)c1ccc2c(c1)CCN2C(=O)C1CCOCC1</smiles>

LY3381916 (7)

Fig. 1 IDO1 inhibitors in the clinical stage 


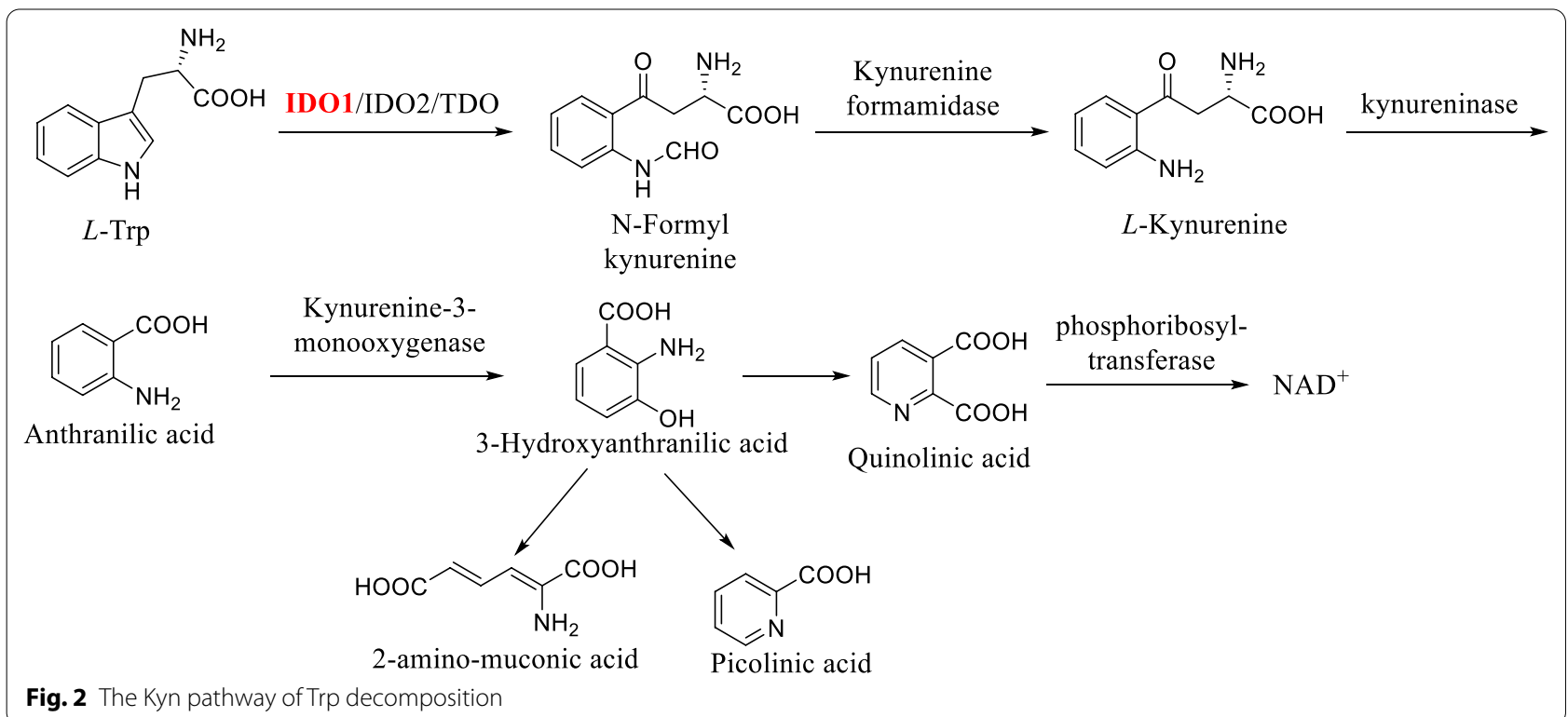

patients $[29,31]$. It has been reported that IDO1 is highly expressed in a variety of tumors, including colorectal cancer, breast cancer, esophageal carcinoma, cervical squamous cell carcinoma, melanoma, pancreatic cancer [32, 33], etc., and IDO1 is also expressed in many other cells, such as vascular cells, antigen-presenting cells (APCs, such as macrophages and DCs), eosinophils, endothelial cells (ECs), fibroblasts, and so on [34]. In addition, IDO1 can be inhibited by the cancer-suppression gene bridging integrator 1 (Bin1) and up-regulated by some cytokines and immune checkpoint molecules such as IFN- $\gamma$, prostaglandin E2 (PGE2), pathogen-associated molecular patterns (PAMPs, such as Toll-like receptor (TLR) 3, TLR4, TLR7, TLR8, and TLR9), damage-associated molecular patterns (DAMPs), immune checkpoint (including PD-1, glucocorticoid-induced TNF receptor-related protein (GITRL), CTLA-4), IL- 6 and TNF- $\alpha$, TGF- $\beta$ to establish an immunosuppressive environment $[33,35]$.

There are two main Trp decomposition pathways concerned with IDO1-mediated tumor immune escape. A nuclear role has been attributed to the Kyn pathway of Trp metabolism, which leads to the consumption of Trp and generation of Kyn metabolites, both responsible for forming an immunosuppressive environment by suppressing the activation of effector cells and promoting the activation of immunosuppressive cells. IDO1 can influence the progression of tumors in three ways. Firstly, IDO1 promotes tumorigenesis and the formation of tolerogenic APCs to enhance the peripheral immune tolerance of tumor-associated antigens (TAAs) [36]. Secondly, overexpression of IDO1 in tolerogenic APCs can inhibit the proliferation and activity of $\mathrm{CD}^{+} \mathrm{T}$ effector cells $\left(T_{\text {effs }}\right)$ and NK cells but induce Tregs and MDSCs through the Kyn pathway indirectly [37]. IDO1 also promotes the expansion and activation of MDSCs and induces polarization of macrophages to a tolerogenic phenotype [38, 39]. Elevated CTLA4 expression of Tregs causes increased IDO1 secretion by DCs [40]. IDO1induced expansion and activation of Tregs, MDSCs, and tolerogenic DCs suppress the activity of antitumor effector T cells $[41,42]$. Finally, induced MDSCs could further inhibit the function of $\mathrm{CD}^{+} \mathrm{T}$ effector cells and NK cells through inflammation environment and induce cancer migration [43].

As shown in Fig. 3a, the expression and function of IDO1 can be regulated by inflammatory molecules (e.g. IFN- $\gamma$, TGF- $\beta /$ PGE2, TNF- $\alpha$, PAMPs/DAMPs) through multiple signaling pathways, such as Janus Kinase (JAK)/ transducer and activator of transcription (STAT), NF- $\mathrm{kB}$, phosphoinositide 3-kinase (PI3K), IFN regulatory factor 1 (IRF1), and RAS-PKC pathway [44, 45], etc. Cyclooxygenase 2 (COX-2) and PGE2 can drive the expression of IDO1 via the PKC and PI3K pathways [46]. In the promoter region of IDO1, there are two IFN- $\gamma$ stimulated response elements (ISREs) and three IFN- $\gamma$ activated sites (GASs), which interact with IRF1 and STAT1, respectively. Studies have shown that IFN- $\gamma$ could potently induce the expression of IDO1, and could robustly activate the (JAK)/STAT and protein kinase $\mathrm{C} \delta$ (PKC $\delta)$ signaling. Accordingly, JAK, STAT1 and IRF1 play an important role in IFN- $\gamma$ mediated IDO1 gene transcription. Autocrine TGF- $\beta$ of a tolerogenic $C D 8^{+} \mathrm{DC}$ could activate IDO1 [37]. Cancer suppression gene Bin1 could downregulate the expression of IDO1 via STAT1 and 

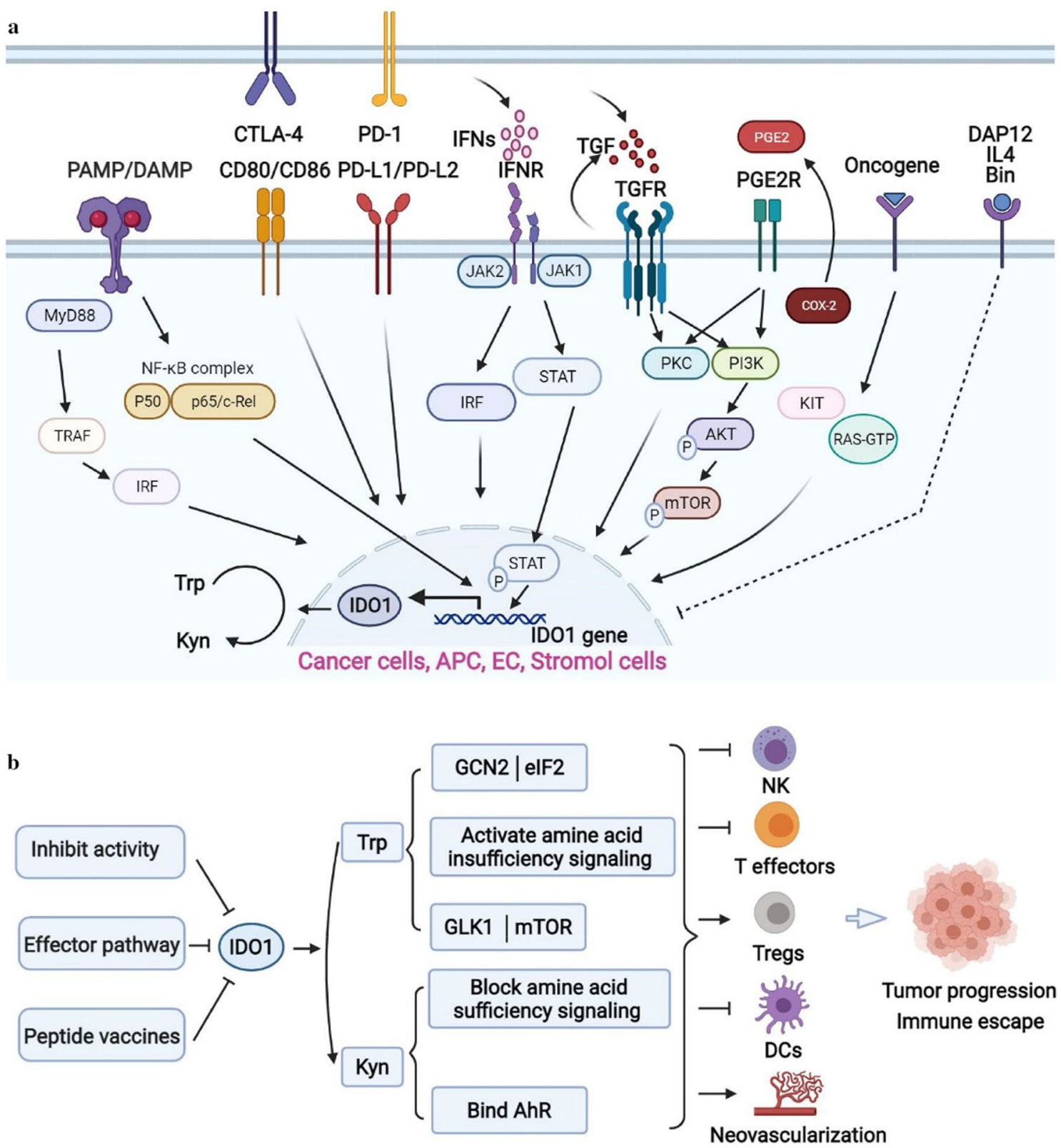

Fig. 3 Mechanism of IDO1 regulation, function and activity. a Regulation of IDO1 expression in many cells through IFN- $/$ /JAK/STAT, KAS, NF-KB and PI3K pathways. $\mathbf{b}$ IDO1 targeting and mechanism of IDO1 in immune escape of cancer cells. IDO1 promotes the immune escape and progression of cancer mainly through GCN2/elF2, GLK1/mTOR, AhR to inhibit the function and differentiation of effector T cells, and there are mainly three strategies to target IDO1 in clinical trials for cancer treatment

NF-kB dependent pathway [34]. IL-6 could upregulate the intestine-specific homeobox (ISX) gene to induce the expression of IDO1 and TDO, and promote the malignant potential of hepatocellular carcinoma cells [47]. In DCs, the expression of IDO1 can be up-regulated by the interaction of its surface CD80/86 with immune checkpoint molecules such as PD-1 and CTLA-4 expressed on the surface of Tregs. Bin1 could block the transcription of IDO1 which is mediated by STAT1 and NF-kB. Other cytokines such as tumor necrosis factor $\alpha$ (TNF- $\alpha$ ), interleukin (IL)-1, IL-6, IFN $\alpha$ and IFN $\beta$, or stimuli including muramyl tripeptide, glucocorticoids, and some infectious pathogens could also regulate the expression of IDO1 [44].

As shown in Fig. 3b, downstream signaling effectors of IDO1 are mainly general control over the 
mammalian target of rapamycin (mTOR), nonderepressible 2 (GCN2), and aryl hydrocarbon receptor (AhR) [44, 48]. Trp consumption by IDO1 could accumulate the uncharged Trp-tRNA to bind and activate GCN2, and then phosphorylates and inhibits eIF2 $\alpha$, leading to the attenuation of RNA transcription and protein translation. Activated GCN2 could induce the apoptosis or cell cycle arrest of effector $\mathrm{T}$ cells and also impacts the differentiation of $\mathrm{CD}^{+} \mathrm{T}$ cells. Another signaling molecule mTOR mediated by IDO1 can lead to anergy of T cells [30, 49]. It has been reported that Kyn is an endogenous ligand of AhR, increased Kyn levels activate the AhR that switches the activity of DCs from immunogenic to tolerogenic, and promotes $\mathrm{CD} 4^{+} \mathrm{T}$ cells differentiation into Treg cells $[50,51]$. All these factors form an immunosuppressive tumor environment to promote the immune escape of tumor cells.

\section{Structural biology of IDO1}

Human IDO1 (hIDO1) is an $\alpha$-helical dioxygenase protein containing a small $\mathrm{N}$-terminal domain (NTD, residues 1-154) and a large C-terminal domain (CTD, residues 155-403) (PDB code: 5WMU, Fig. 4a). The CTD is made up of thirteen $\alpha$-helices (G-S) and two $3_{10}$ helices, four long helices (G, I, Q, and S) of which are ranged with the heme site (HEM) and form hydrophobic interactions with the neighboring helix, and the side chains of helices $\mathrm{K}, \mathrm{L}$, and $\mathrm{N}$ are also involved in heme-protein interactions [52-55]. Trp, the hIDO1's binding substrate, induces the organization of the highly disordered JKLoop of the CTD into a $\beta$-hairpin structure. These main helices create the heme-binding pocket together ("Pocket A", Fig. 4b) [56, 57], the imidazole moiety of His346 in helix Q greatly contributes to the heme-protein interactions as a crucial endogenous ligand. While the NTD is located on top of it and consists of six $\alpha$-helices, two short $\beta$-sheets, and three $3_{10}$ helices. There are extensive contacts between these two domains by a combination of numerous hydrophobic interactions and "salt bridges" [58]. Moreover, the "Pocket B" at the entrance of the active site is comprised of Phe226, Phe227, Arg231, Ile354, and Leu384, etc., and participates in stabilizing protein-inhibitor interactions [56, 59]. Mutants of Phe226, Phe227, and Arg231 have significantly reduced the dioxygenase activity, supporting the hypothesis that the residues of "Pocket B" directly affect substrate recognition by $\pi-\pi$ stacking interactions and hydrophobic interactions. Additionally, the benzimidazole-based compound reported by Alberto Massarotti and co-workers $[60,61]$ has a unique binding mode within the active site of IDO1 (Fig. 4b, c). The 3-bromopyrrole moiety extends into an extra "Pocket C" consisting of Gly236, Lys238, Ala260, Gly261, Gly262, Ser263, Phe291, Met295, etc.
Taken together, the structural features provide a basis for the structure-based design of IDO1 inhibitors.

\section{ID01 inhibitors and peptide vaccines in clinical trials}

Given the biological importance of IDO1 in cancer immunotherapy, IDO1 has become an attractive target. To date, a large number of IDO1 inhibitors have been reported, some of them, including Epacadostat, BMS986205, Indoximod, PF-06840003, etc., have advanced into clinical trials for cancer treatment (Fig. 1). Besides, several peptide vaccines targeting IDO1 have also entered the clinical assessment for examining the efficacy and safety and show promise for cancer therapy. Since the IDO1 inhibitors and peptide vaccines in clinical trials have been described previously in the decent review article [62], only recent updates on IDO1 inhibitors in clinical trials are shown in Table 1.

\section{Indoximod (1-methyl-D-tryptophan, 1MT, NLG-8189)}

Indoximod is a competitive IDO1 inhibitor and has been granted orphan-drug designation by the US FDA for the treatment of stage IIb to stage IV melanoma. Studies have reported that indoximod does not directly inhibit the enzymatic activity of IDO or TDO, but instead opposes the effects elicited by these enzymes [69]. It could mimic Trp to reverse the inhibition of mTORC1 which is a central regulator for cell growth $[70,71]$. There are 17 clinical studies for indoximod registered in ClinicalTrails website (https://clinicaltrials.gov) with 12 clinical studies completed, 1 clinical study recruiting, 1 clinical study active, not recruiting, 2 clinical studies terminated (the clinical trial NCT00739609 was lack of enrollment, and the trial NCT03301636 was terminated by the sponsor, not related to efficacy, safety or feasibility), 1 clinical study withdrawn (no results posted). Clinical results indicated that when used as a single agent, indoximod exerted little antitumor efficacy, while combination of indoximod with other therapies including cancer vaccines (Sipuleucel-T/ Adenovirus-p53 transduced dendritic cell (DC) Vaccine), checkpoint inhibitors (pembrolizumab/nivolumab/Ipilimumab) and chemotherapy showed markedly enhanced the antitumor efficacy, Indoximod was well-tolerated at doses up to $2000 \mathrm{mg}$ BID [72, 73].

\section{Epacadostat (INCB024360)}

Epacadostat, a Trp competitive inhibitor, has over 1000fold selectivity to IDO1 over IDO2 or TDO. The halflife of epacadostat is 2.4-3.9 h [74]. In vitro and in vivo (tumor-bearing syngeneic mice) studies showed that epacadostat could reduce tumor growth and promote the proliferation of T cells and NK cells [75]. 55 Clinical studies for epacadostat have been reported, with 7 clinical 

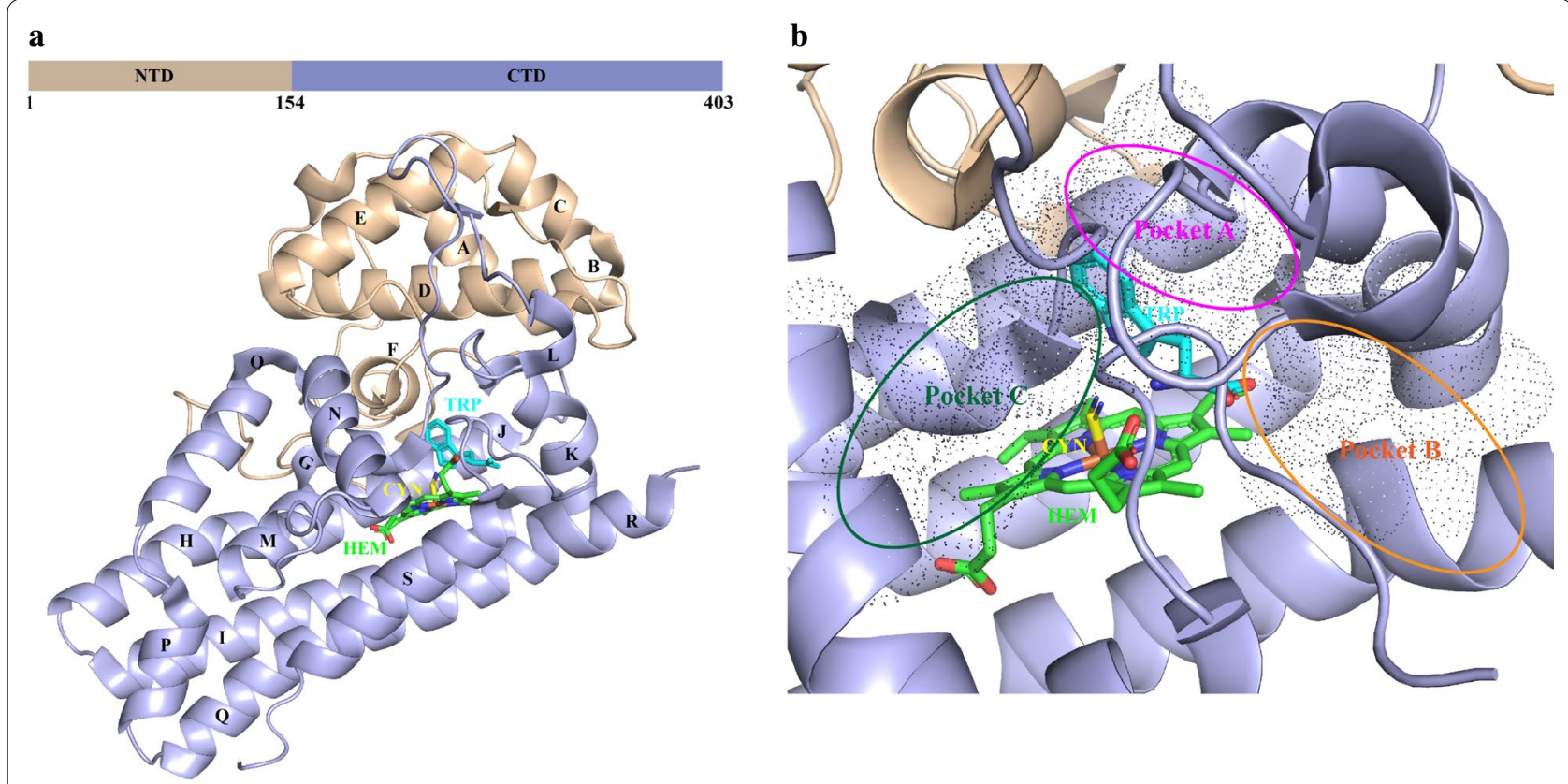

c

Pocket C

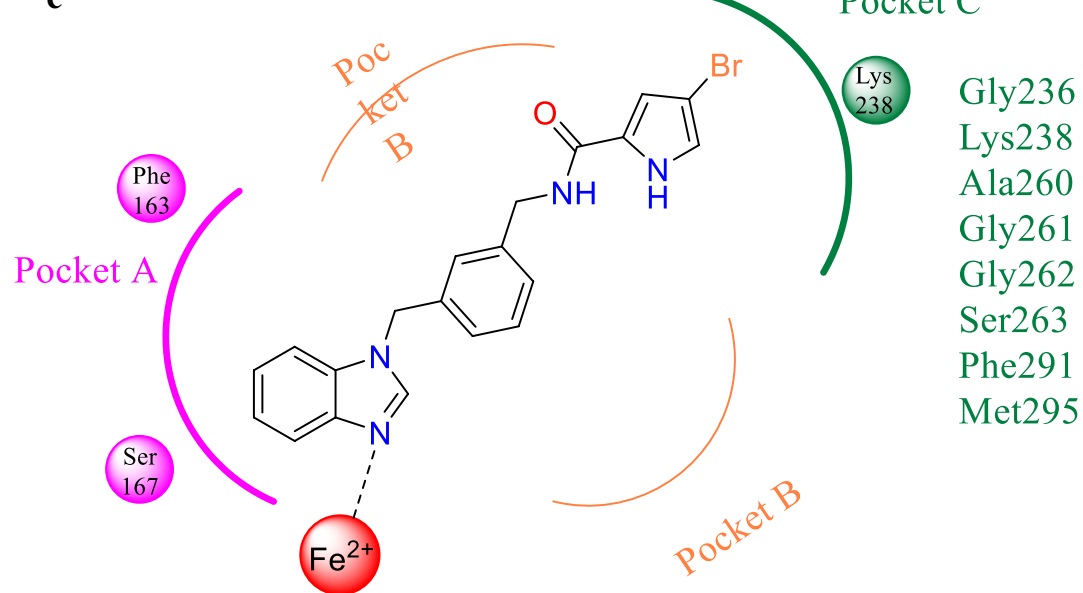

Fig. 4 Structural basis of IDO1. a The overall structure of human IDO1 (PDB code: 5WMU). The N-terminal and C-terminal domains are represented by aurantium and purple ribbons, respectively. The helices $\mathrm{A}-\mathrm{S}$ are named in the order of appearance in the primary sequence. The substrate Trp is colored in cyan and the heme site is colored in green. $\mathbf{b}$ Three binding pockets within the active site. The three pockets are colored in magentas ("Pocket $A^{\prime \prime}$ ), orange ("Pocket B"), and jasper ("Pocket C"), respectively. c Schematic representation of the binding model of the benzimidazole compound within the active site of IDO1

studies completed, 8 clinical studies recruiting, 18 clinical studies active, not recruiting, 8 clinical studies terminated, 2 clinical studies not yet recruiting, 1 clinical study suspended, 11 clinical studies withdrawn.

Preclinical studies showed that epacadostat and immune checkpoint blockade had a synergy effect, and several clinical trials were initiated to study the combination of epacadostat with either pembrolizumab (NCT03414229, NCT02364076, NCT03291054, etc.), ipilimumab (NCT01604889), nivolumab
(NCT02327078, NCT03347123, NCT03348904, etc.). In the trial of NCT03414229, the response rate for melanoma was reported, the objective remission rate (ORR) was $57 \%$, the disease control rate (DCR) was $86 \%$, the ORR and DCR for renal cell carcinoma was $40 \%$ and $80 \%$, respectively. In the trial of NCT01604889, the objective response rate was $18 \%$, and stable disease was observed in $26 \%$ of the metastatic melanoma patients [76]. In the phase I/II trial of NCT02327078, epacadostat (100 mg BID or $300 \mathrm{mg}$ 


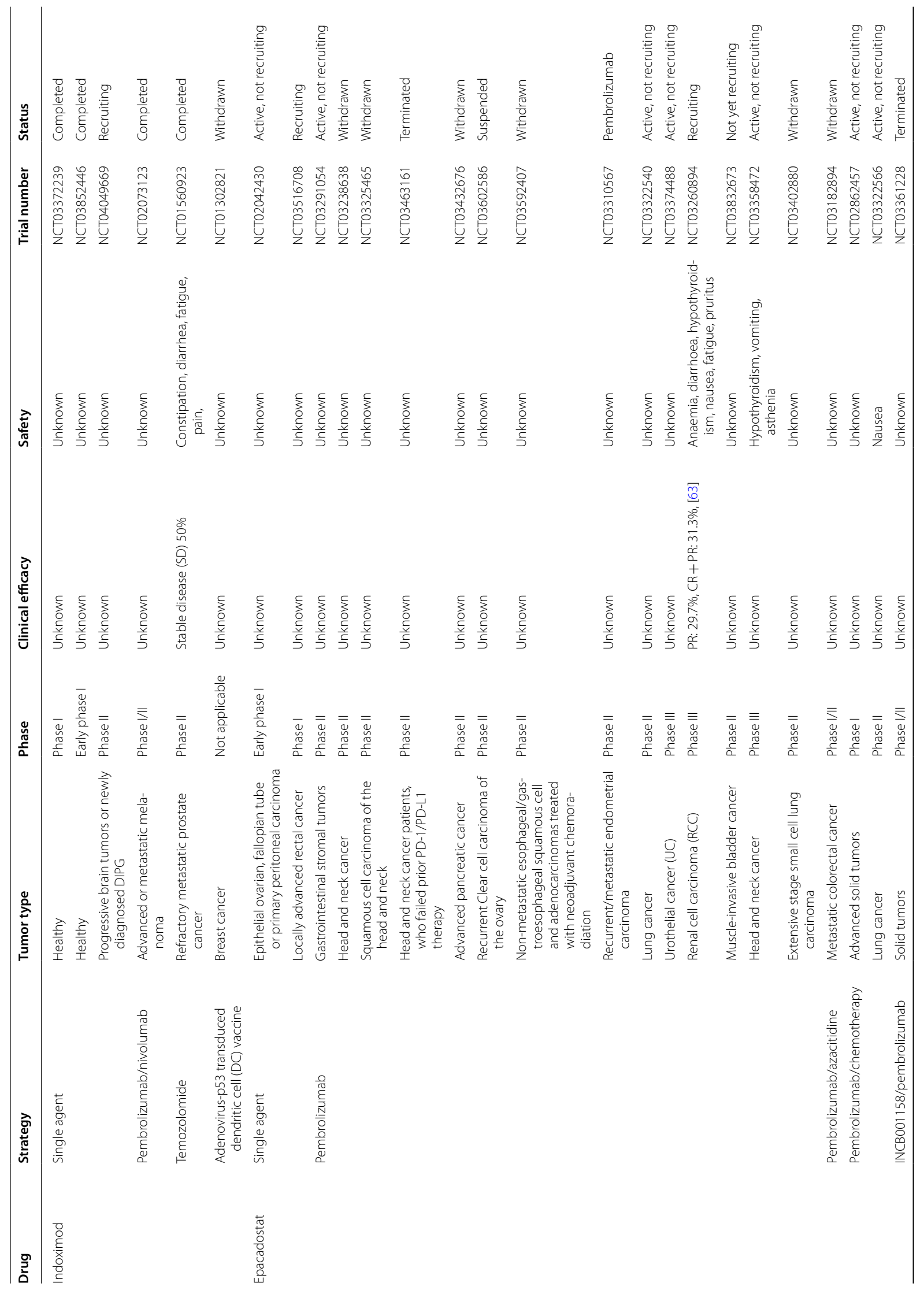




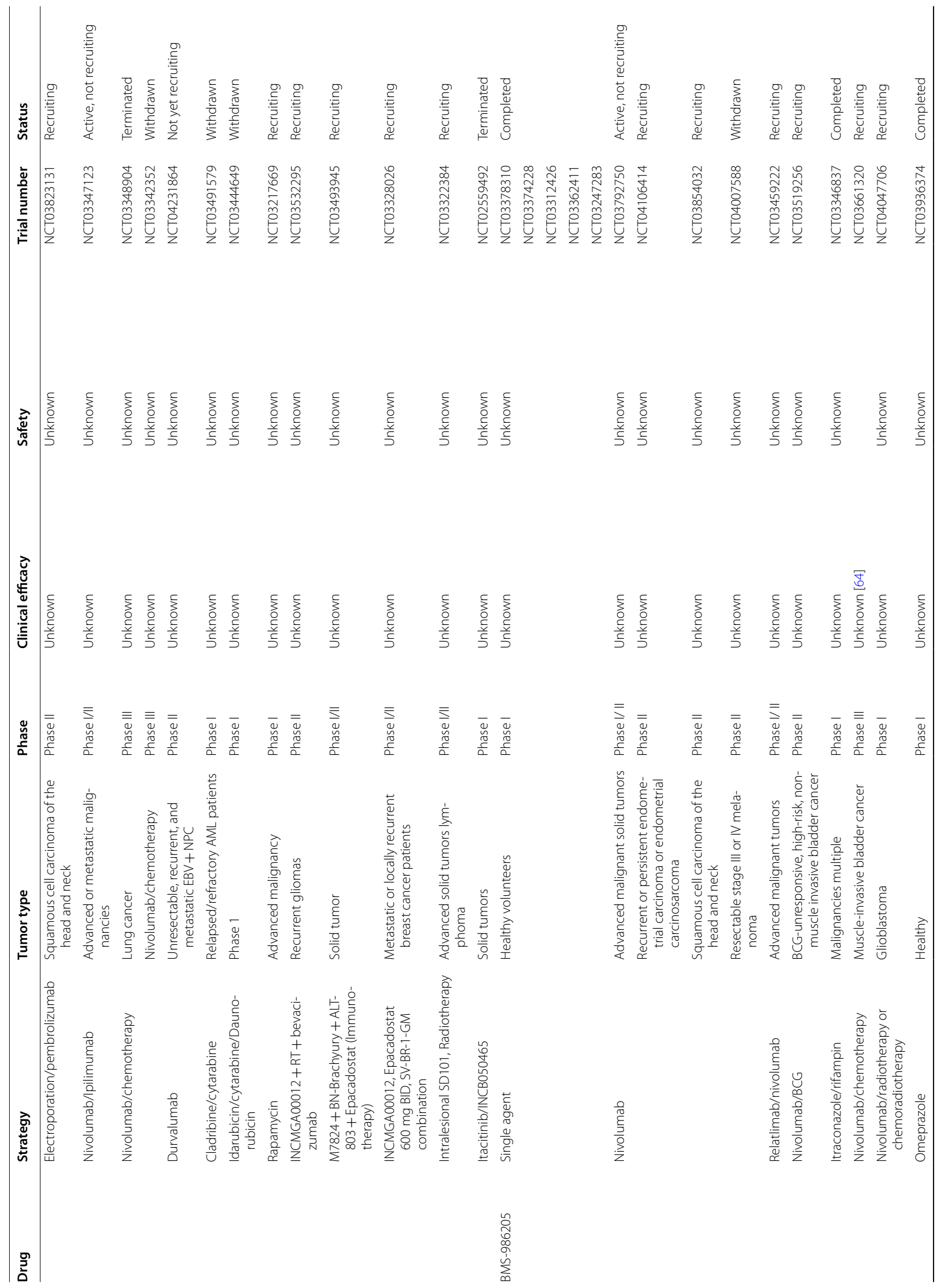




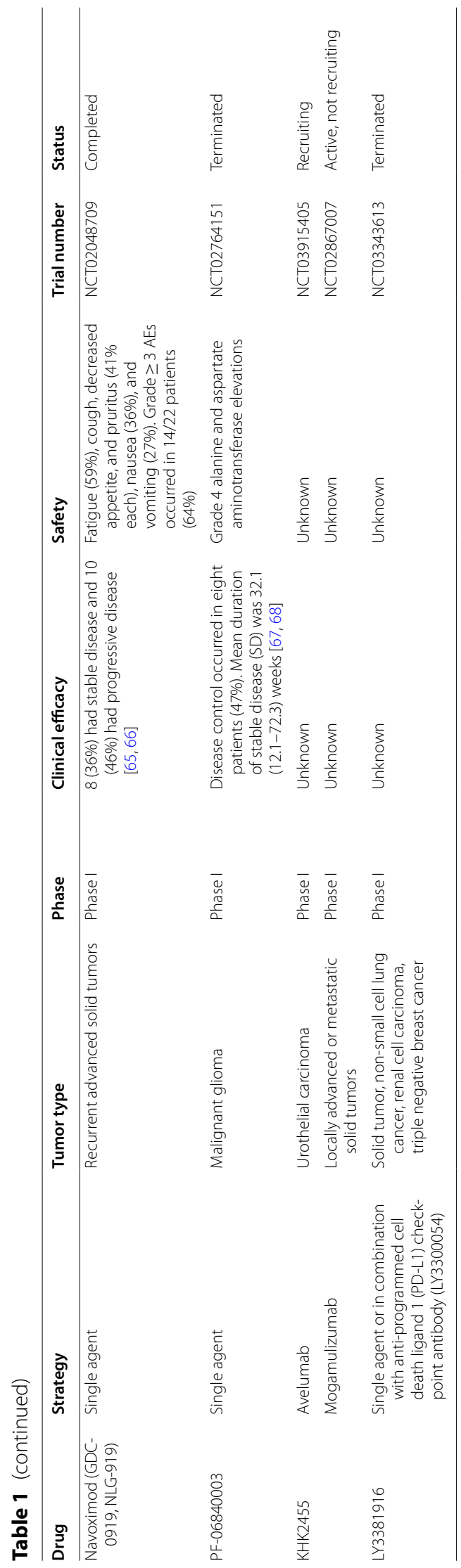

BID) was combined with nivolumab (240 mg every 2 weeks), the response rate was $62 \%$ (6/8 patients receiving $100 \mathrm{mg}$ BID and 25/42 patients receiving $300 \mathrm{mg}$ BID), and toxicities (such as ALT increase, rash and pneumonitis) were observed in $13 \%$ of patients receiving epacadostat (100 mg BID) and $48 \%$ of patients receiving epacadostat (300 $\mathrm{mg}$ BID) [77]. A phase III study (NCT02752074) was designed to investigate the efficacy, safety, and tolerability by combining pembrolizumab with epacadostat or placebo in participants with unresectable or metastatic melanoma, but the results were negative [63]. The disappointing results hampered the development of IDO1 inhibitors, and several phase III trials were terminated and withdrawn. In these terminated and withdrawn clinical trials, 13 studies (NCT03310567, NCT03432676, NCT01685255, NCT03361228, NCT02575807, NCT03463161, NCT03348904, NCT03602586, NCT03238638, NCT03342352, NCT03402880, NCT01604889, and NCT03325465) were due to the reasons including the low enrollment. One study (NCT03832673) was not approved by the Italian Medicines Agency (AIFA). One study (NCT03592407) was due to the safety concerns. One study (NCT03182894) was due to the changes related to the investigational agent.

\section{BMS-986205}

Linrodostat mesylate (BMS-986205), an orally available IDO1 inhibitor, can specifically bind to IDO1, but not IDO2 or TDO. BMS-986205 can reverse the immunosuppression system in cancer patients by inhibiting IDO1 and decreasing the Kyn levels of tumor cells. There are 24 clinical studies for BMS-986205, with 8 clinical studies completed, 11 clinical studies recruiting, 2 clinical studies active, not recruiting, 3 clinical studies withdrawn. The trial (NCT04007588) was withdrawn because of the slow accrual, and another 2 studies (NCT03386838 and NCT03417037) were withdrawn because of the changed business objectives. Several phase I/II studies (NCT03192943, NCT02658890) suggest that combining BMS-986205 with nivolumab is safe and could boost response rates among patients with bladder and cervical cancers $(46 \%$ and $25 \%$, respectively), and the recommended dose of BMS986205 was $100 \mathrm{mg}$ for further study [78]. Based on these encouraging results, 13 clinical trials were performed to study the effect of BMS-986205 combined with nivolumab or other drugs such as ipilimumab, relatlimab, chemotherapy, Bacillus Calmette-Guerin (BCG), etc. on non-small cell lung cancer, metastatic or unresectable melanoma, advanced gastric cancer, and other advanced malignant solid tumors [64]. 


\section{Navoximod (GDC-0919, NLG-919)}

Navoximod is an orally active IDO1 inhibitor. In vitro studies showed that navoximod could restore the $\mathrm{T}$ cell function, and in vivo studies suggested that after navoximod treatment, approximately $50 \%$ of mice had reduced Kyn levels in plasma. A completed phase I clinical study (NCT02048709) of navoximod monotherapy in recurrent advanced solid tumors showed that $8(36 \%)$ patients and $10(46 \%)$ patients had stable disease and progressive disease, respectively. And clinical adverse events mainly include fatigue (59\%), pruritus (41\%), nausea (36\%), Grade $\geq 3$ adverse effects (AEs) occurred in 14/22 patients (64\%) [65]. Another completed phase I clinical study (NCT02471846) of navoximod combined with atezolizumab to treat locally advanced or metastatic solid tumors showed that $6(9 \%)$ dose-escalation patients achieved partial response, and 10 (11\%) expansion patients achieved partial or complete response. And clinical adverse events mainly include fatigue, rash, and chromaturia. the oral dose of navoximod remains safe and effective up to $800 \mathrm{mg}$ BID [66].

\section{PF-06840003}

PF-0684003, a highly selective and orally bioavailable IDO1 inhibitor, can cross the blood-brain barrier (BBB). It has been reported that PF-0684003 could restore the function of $\mathrm{T}$ cells in vitro, and reduce the Kyn levels to enhance the antitumor effect of the checkpoint inhibitors in vivo (syngeneic mouse tumor models) [79]. A phase I study of PF-0684003 (single agent) was performed in patients with recurrent malignant Glioma (NCT02764151) to study the safety, pharmacokinetics/ pharmacodynamics, and preliminary efficacy and to determine the maximum tolerated dose (MTD). Patients were divided into four groups: $125 \mathrm{mg}$ once daily (QD, $n=2), 250 \mathrm{mg}$ once daily (QD, $n=4), 250 \mathrm{mg}$ twice-daily (BID, $n=3$ ), $500 \mathrm{mg}$ twice-daily (BID, $n=8$ ). Results showed that disease control occurred in eight patients (47\%). And the mean duration of stable disease (SD) was 32.1 (12.1-72.3) weeks, four patients experienced serious adverse events (SAEs) [67, 68]. This compound had a prolonged half-life and could cross the blood-brain barrier. But this study was prematurely terminated by the sponsor, and not to pursue marketing approval for the indication of malignant glioma.

\section{Other inhibitors}

There are 2 ongoing phase I clinical trials for KHK2455 (NCT03915405 and NCT02867007). The trial (NCT03915405) is a two-part (dose-escalation, doseexpansion), multicenter, open-label study of KHK 2455 in combination with avelumab in adult subjects with urothelial carcinoma. The trial (NCT02867007) is to characterize the safety, tolerability, and determine the maximum tolerated dose (MTD) or the highest protocol-defined dose of KHK2455 administered orally in combination with mogamulizumab (anti-CCR4 antibody) to subjects with locally advanced or metastatic solid tumors [80]. One terminated phase I clinical trial (NCT03343613) for LY3381916 was to evaluate the safety of LY3381916 administered alone or in combination with the anti-PD-L1 antibody LY3300054, and was terminated due to strategic business decision.

\section{Peptide vaccines for IDO1}

Mads Hald Andersen and Inge Marie Svane's studies have found spontaneous IDO1 specific $\mathrm{CD}^{+}$and $\mathrm{CD}^{+} \mathrm{T}$ cells in tumor infiltrate and peripheral blood of tumor patients, and identified IDO1 specific HLAA2-restricted epitopes to induce specific $\mathrm{CD}^{+} \mathrm{T}$ cells that recognize and kill IDO1-positive cells. Further studies showed that IDO1 specific $\mathrm{T}$ cells could also enhance the response of other T cells. A phase I study (NCT01219348) was performed to study the efficiency and safety of the HLA-A2 restricted IDO peptide to treat NSCLC. 15 participants with advanced NSCLC were enrolled. Results showed that the median overall survival (OS) was 25.9 months ( $>2$ years), progression-free survival (PFS) was $6 \sim 7$ months, with no grade 3 or 4 toxicities [81, 82]. Based on these promising results, another three clinical trials (NCT01543464, NCT02077114, and NCT03047928) were performed to combine nivolumab or ipilimumab or chemotherapy with IDO peptide to study the synergistic anti-tumor effects [83]. Besides, there are also other peptides that could regulate IDO1 in the study.

\section{Medicinal chemistry strategies for the development of IDO1 inhibitors in clinical trials \\ Epacadostat (INCB024360)}

As shown in Fig. 5, the hydroxyamidine chemotype was discovered as a key pharmacophore for IDO1 inhibition. With the assistance of high-throughput screening (HTS), the Incyte Corporation [84] initially identified 4-amino-1,2,5-oxadiazole-3-carboximidamide (compound 8$)$ as an IDO1 inhibitor $\left(K_{i}=1.5 \mu \mathrm{M}\right)$, correlative absorption spectroscopy also confirmed direct binding to the heme site. In addition, compound $\mathbf{8}$ inhibited TDO with an $\mathrm{IC}_{50}$ of $10 \mu \mathrm{M}$, showing selectivity to IDO1. Subsequent aniline replacement of the benzylamine produced a library of carboximidamides. Intriguingly, compound 9 bearing the phenyl group showed improved cellular potency $\left(\mathrm{HeLa}\right.$ cell $\left.\mathrm{IC}_{50}=0.49 \mu \mathrm{M}\right)$ than the hit compound 8 (HeLa cell $\mathrm{IC}_{50}=1 \mu \mathrm{M}$ ), albeit with 
<smiles>Nc1nonc1/C(=N\O)NCc1ccccc1</smiles>

8

IDO1 $\mathrm{K}_{i}=1.5 \mu \mathrm{M}$

HeLa cell $\mathrm{IC}_{50}=1 \mu \mathrm{M}$<smiles>Nc1nonc1/C(=N\O)Nc1ccccc1</smiles>

9

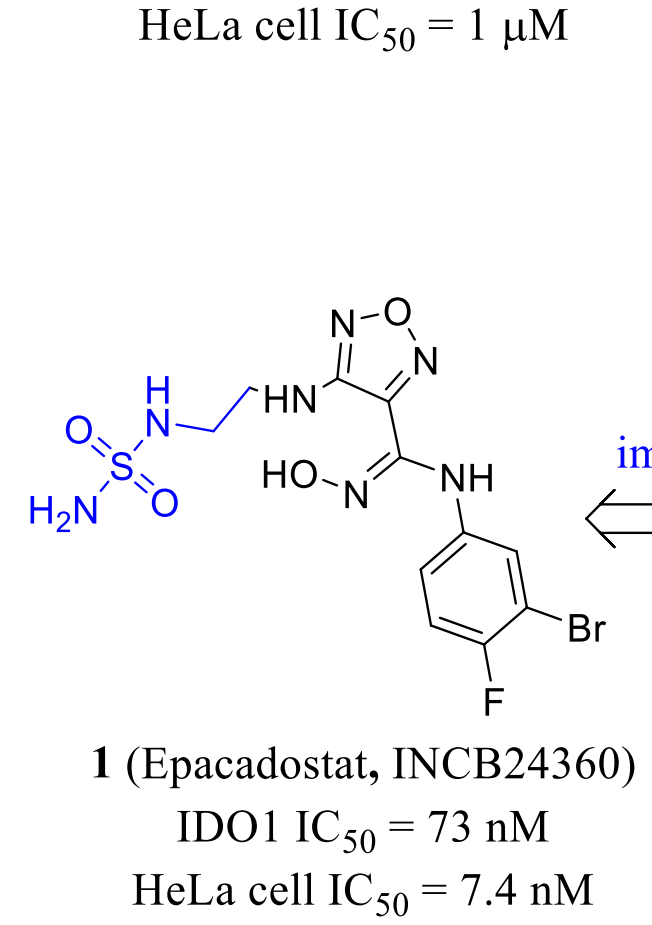

Fig. 5 The optimization of epacadostat (INCB24360)
ADME improvement

HeLa cell $\mathrm{IC}_{50}=0.49 \mu \mathrm{M}$

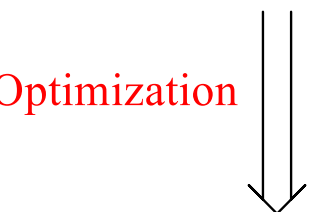<smiles>Nc1nonc1/C(=N\O)Nc1ccc(F)c(Cl)c1</smiles>

10 (INCB14943)

IDO1 $\mathrm{IC}_{50}=67 \mathrm{nM}$

HeLa cell $\mathrm{IC}_{50}=19 \mathrm{nM}$

Table 2 The PK profiles of epacadostat (INCB024360)

\begin{tabular}{|c|c|c|c|c|c|c|}
\hline Species & $\mathrm{CL}(\mathrm{L} / \mathrm{h} / \mathrm{kg})$ & $V_{s s}(\mathrm{~L} / \mathbf{k g})$ & iv $t_{1 / 2}(\mathrm{~h})$ & AUC ( $\mu \mathrm{M} \mathrm{h})$ & $F(\%)$ & $\begin{array}{l}t_{1 / 2} \\
(\mathrm{~h})\end{array}$ \\
\hline Rat & 1.1 & 2.0 & 1.4 & 1.3 & 11 & 2.2 \\
\hline Dog & 0.5 & 0.7 & 3.1 & 29 & 59 & 4.9 \\
\hline Cyno & 0.8 & 1.8 & 3.3 & 9.3 & 33 & 2.7 \\
\hline
\end{tabular}

$\mathrm{CL}$, plasma clearance; $V_{s s^{\prime}}$ volume distribution stead state; $t_{1 / 2}$, half-life; AUC, area under the concentration-time curve; $F$, Oral bioavailability; iv, intravenous injection; Cyno, cynomologous monkeys

slightly decreased enzymatic activity against IDO1 $\left(\mathrm{IC}_{50}=3.2 \mu \mathrm{M}\right)$. Among the phenyl substituted derivatives, the $m$-chloro-p-fluoro 10 (NCB14943) showed significant improvement in both enzymatic activity and cellular potency (>100-fold, IDO1 $\mathrm{IC}_{50}=67 \mathrm{nM}$, HeLa $\left.\mathrm{IC}_{50}=19 \mathrm{nM}\right)$ as well as selectivity (IDO2 $\mathrm{IC}_{50}>10 \mu \mathrm{M}$,
TDO $\left.\mathrm{IC}_{50}>50 \mu \mathrm{M}\right)$. In vivo studies demonstrated that upon subcutaneous administration at $75 \mathrm{mg} / \mathrm{kg}$ twice daily, compound 10 caused $50 \%$ of tumor growth control (TGC) in naive C57BL/6 mice. Further structural modifications showed that secondary amino substituents at the 3 -position of the furazan were preferred over the tertiary 
a

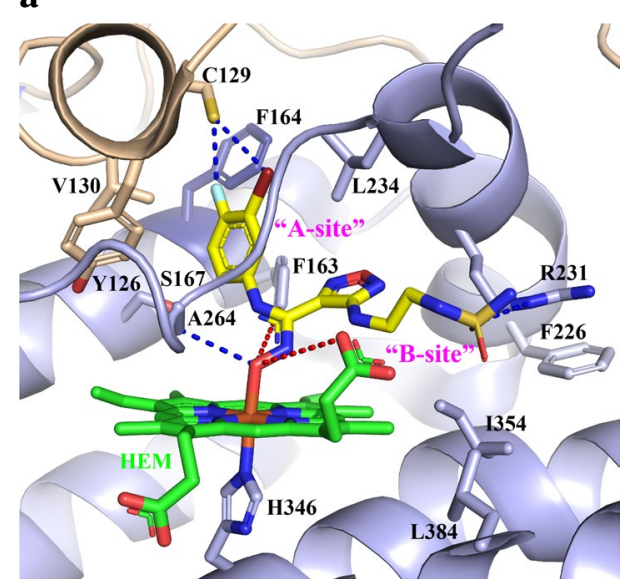

b

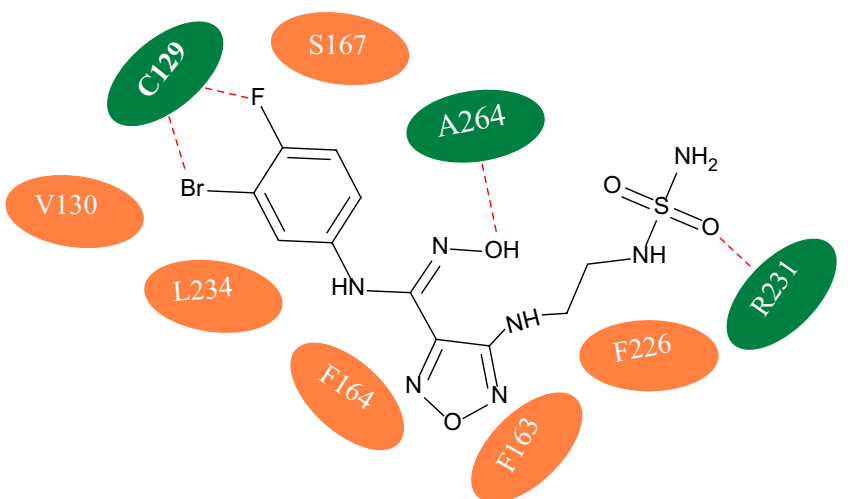

Fig. 6 a Crystal structure of the IDO1-epacadostat complex (PDB code: 5WN8). The heme site is colored in green. The inhibitor epacadostat is displayed in yellow stick. The H-bonding interactions between epacadostat and the IDO1 protein matrix are indicated by the blue dotted lines, and the intramolecular $\mathrm{H}$-bonds within epacadostat are indicated by the red dotted lines. $\mathbf{b}$ Schematic illustration of the IDO1-epacadostat interactions.

Table 3 The PK profiles of BMS-986205

\begin{tabular}{lllll}
\hline Species & $\mathbf{C L}(\mathbf{m L} / \mathbf{m i n} /$ & $\boldsymbol{V}_{\mathbf{s s}}(\mathbf{L} / \mathbf{k g})$ & $\boldsymbol{t}_{\mathbf{1 / 2}}(\mathbf{h})$ & $\begin{array}{l}\boldsymbol{F} \\
\mathbf{( \% )}\end{array}$ \\
\hline Rat & 27 & 3.8 & 3.9 & 4 \\
Dog & 25 & 5.7 & 4.7 & 39 \\
Cyno & 19 & 4.1 & 6.6 & 10 \\
\hline
\end{tabular}

$\mathrm{CL}$, plasma clearance; $V_{\mathrm{ss}}$, volume distribution stead state; $t_{1 / 2}$, half-life; $F$, oral bioavailability; Cyno, cynomologous monkeys

amino groups for the activity. It is believed that the secondary amino side chain was exposed to the solvent region of IDO1, thus maintaining preferable biochemical potency. Finally, they obtained the clinical candidate epacadostat (1, INCB24360, IDO1 $\mathrm{IC}_{50}=73 \mathrm{nM}$, HeLa $\left.\mathrm{IC}_{50}=7.4 \mathrm{nM}\right)$ with good oral bioavailability across multiple species [85]. As shown in Table 2, epacadostat achieved good oral bioavailability $(F=11 \%, 59 \%, 33 \%$ in rats, dogs, and cynomolgus monkeys, respectively) and a long half-life period $\left(t_{1 / 2}=2.2 \mathrm{~h}, 4.9 \mathrm{~h}, 2.7 \mathrm{~h}\right.$ in rats, dogs and cynomolgus monkeys, respectively) without significant loss of the enzyme activity. The PK profiles of $\mathbf{1}$ in these species demonstrated good exposure (AUC $=1.3 \mu \mathrm{M} \cdot \mathrm{h}, 29 \mu \mathrm{M} \cdot \mathrm{h}, 9.3 \mu \mathrm{M} \cdot \mathrm{h}$ in rats, dogs, and cynomolgus monkeys, respectively) and moderate permeability $\left(V_{\mathrm{ss}}=2.0 \mathrm{~L} / \mathrm{kg}, 0.7 \mathrm{~L} / \mathrm{kg}, 1.8 \mathrm{~L} / \mathrm{kg}\right.$ in rats, dogs, and cynomolgus monkeys, respectively), which was in good agreement with the vitro clearance data $(\mathrm{CL}=1.1 \mathrm{~L} / \mathrm{h} / \mathrm{kg}, 0.5 \mathrm{~L} / \mathrm{h} / \mathrm{kg}, 0.8 \mathrm{~L} / \mathrm{h} / \mathrm{kg}$ in rats, dogs, and cynomolgus monkeys, respectively). After oral dosing at $30 \mathrm{mg} / \mathrm{kg}$ in CT26 model mice, epacadostat suppressed CT26 tumor growth effectively $(\mathrm{TGC}=56 \%$ ).
What's more, epacadostat showed exquisite selectivity over other related dioxygenases (>1000-fold), and no toxicity in vitro toxicological studies. However, it has been reported that compared with pembrolizumab alone, epacadostat combined with PD-1 monoclonal antibody pembrolizumab did not exhibit significantly improved PFS in the treatment of unresectable or metastatic melanoma [63]. The failure of phase III study of epacadostat posed the need for in-depth insights into the IDO1 pathway in cancers and the rational design of IDO1 inhibitors [86].

Syun-Ru Yeh et al. [29] obtained the crystal structure of IDO1 in complex with epacadostat in 2017 (Fig. 6a). The binding model (Fig. $6 \mathrm{~b}$ ) revealed that there was a previously unknown O-based coordination bond between the heme iron and epacadostat, which was simultaneously stabilized by an H-bonding interaction with A264 in the DE-Loop, a fluorine-sulfur contact offered by $\mathrm{F}$ and $\mathrm{Br}$ atoms with the sulfhydryl of $\mathrm{C} 129$ as well as two intramolecular $\mathrm{H}$-bondings of epacadostat. The benzene ring occupied the "A-site" and filled into a hydrophobic pocket formed by a series of residues, including F163, L234, F164, V130, Y126, and S167. On the other hand, the polar side chain of the furazan ring was extended into the "B-site" consisting of F226, R231, I354, L384, and a new H-bond interaction with R231 was observed.

\section{BMS-986205}

BMS-986205 is an inhibitor with a unique dynamic apo-IDO1 binding model [87]. It displayed potent inhibition of kynurenine (kyn) production in HeLa cells $\left(\mathrm{IC}_{50}=1.7 \mathrm{nM}\right)$ and HEK293 cells $\left(\mathrm{IC}_{50}=1.1 \mathrm{nM}\right)$ but 

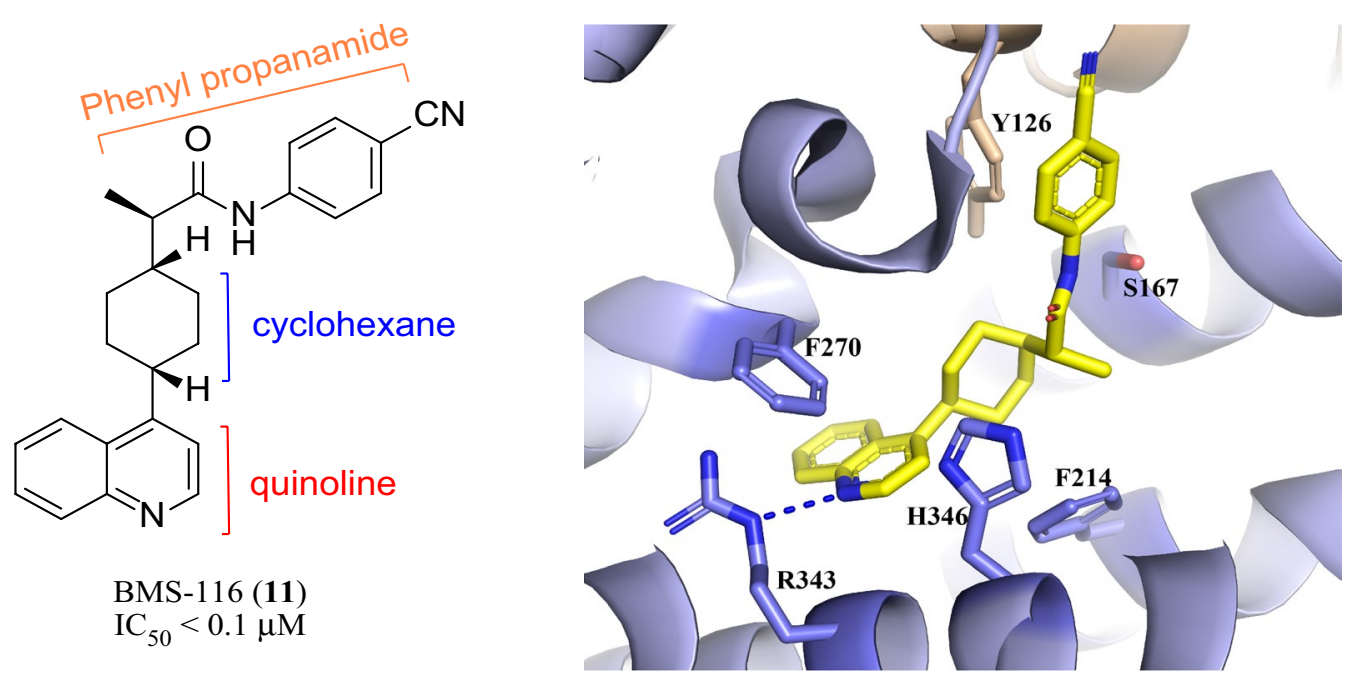

Fig. 7 The binding mode of BMS-116 with IDO1 (PDB code: 6AZW). The inhibitor BMS-116 is displayed in yellow stick. The H-bonding interaction is indicated by the blue dotted lines<smiles>O=C1CC(c2c[nH]c3ccccc23)C(=O)N1</smiles>

12

$\mathrm{IC}_{50}=3.0 \mu \mathrm{M}$<smiles></smiles><smiles>[R16]C=C</smiles><smiles>C#CCCCCC</smiles>

14

$$
\mathrm{IC}_{50}=120 \mathrm{nM}
$$

$\mathrm{IC}_{50}=54 \mu \mathrm{M}$

HeLa cell $\mathrm{IC}_{50}=1 \mu \mathrm{M}$

HeLa cell $\mathrm{IC}_{50}=13 \mu \mathrm{M}$

Fig. 8 The discovery of PF-06840003

not TDO $\left(\mathrm{IC}_{50}>20 \mu \mathrm{M}\right)$. BMS-986205 showed good oral exposure and efficacy in vivo assays. The pharmacokinetic profiles in rats, dogs, and cynomolgus monkeys were summarized in Table 3. After an intravenous administration of $0.5 \mathrm{mg} / \mathrm{kg}$, the corresponding clearance, $V_{\mathrm{ss}}$, half-life and bioavailability in rats were $27 \mathrm{~mL} / \mathrm{min} / \mathrm{kg}$, $3.8 \mathrm{~L} / \mathrm{kg}, 3.9 \mathrm{~h}$ and $4 \%$, respectively. The results in dogs at $0.5 \mathrm{mg} / \mathrm{kg}$ were $25 \mathrm{~mL} / \mathrm{min} / \mathrm{kg}, 5.7 \mathrm{~L} / \mathrm{kg}, 4.7 \mathrm{~h}$ and $39 \%$, respectively. In cynomolgus monkeys with the same 
Table 4 The PK profiles of PF-06840003

\begin{tabular}{lcllll}
\hline Species & $\mathrm{CL}(\mathbf{m L} / \mathbf{m i n} / \mathbf{k g})$ & $\boldsymbol{V}_{\mathbf{s s}}(\mathrm{L} / \mathbf{k g})$ & $\boldsymbol{t}_{\mathbf{1 / 2}}(\mathrm{h})$ & $\boldsymbol{F}(\%)$ & $\begin{array}{l}\text { AUC }(\mathbf{n g ~ h} / \\
\mathbf{m L})\end{array}$ \\
\hline Rat & 3.7 & 0.639 & 2.42 & 94.0 & 6940 \\
Dog & 24.3 & 0.957 & 0.840 & 18.6 & 237 \\
Human & 0.64 & 1.1 & 19 & 64 & $\mathrm{ND}$ \\
\hline
\end{tabular}

$\mathrm{CL}$, plasma clearance; $V_{s s^{\prime}}$ volume distribution stead state; $t_{1 / 2}$, half-life; $F$, Oral bioavailability; AUC, area under the concentration-time curve

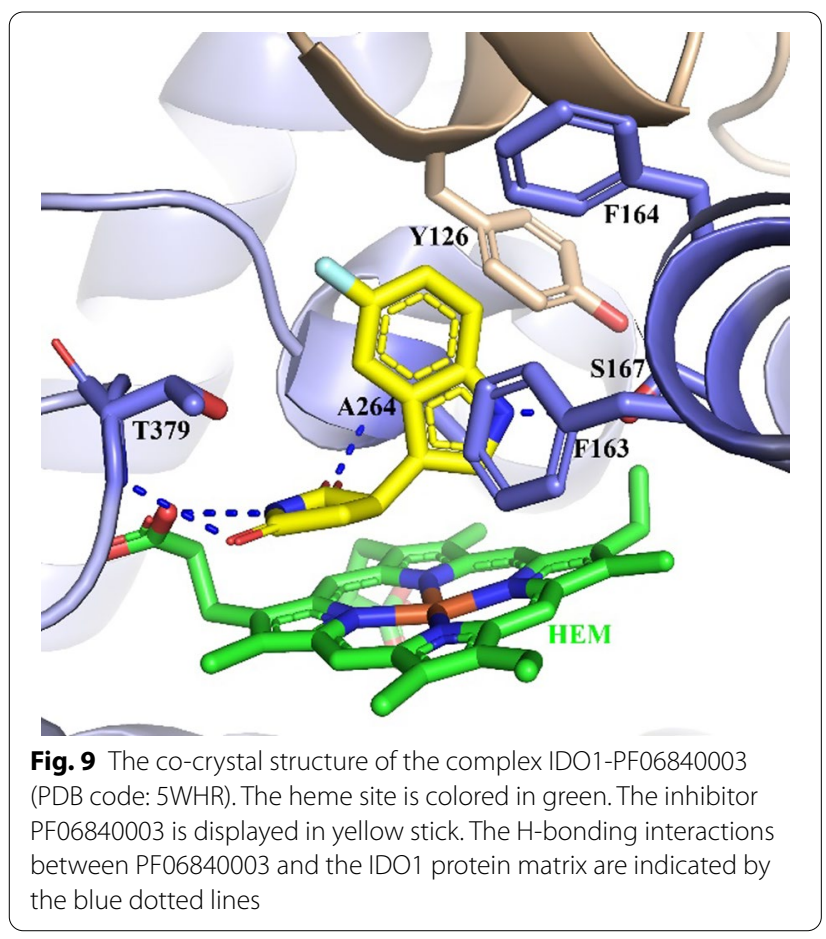

doses as rats, the results were $19 \mathrm{~mL} / \mathrm{min} / \mathrm{kg}, 4.1 \mathrm{~L} / \mathrm{kg}$, $6.6 \mathrm{~h}$ and $10 \%$, respectively.

The X-ray crystallographic structure of BMS-116 (11, $\mathrm{IC}_{50}<0.1 \mu \mathrm{M}$, Fig. 7, PDB: 6AZW) [88], an analog of BMS-986205, revealed a putative substrate-binding site, where the cyanophenyl group in BMS-116 bond with Y126 via $\pi-\pi$ interactions and had hydrogen-bond interaction with S167. The quinoline ring occupied an additional hydrophobic pocket formed by F270, F214, H346 and R343, and formed "edge-to-face" interaction with F270 and $\mathrm{H}$-bonding with R343. In addition, the cyclohexane group also played an auxiliary role in guiding the quinoline ring to the new binding pocket. The unique binding mode of BMS-116 may provide a structural basis for the design of new IDO1 inhibitors.

\section{PF-06840003}

Among indoles series, PF-06840003 (EOS200271, 3), developed by iTeos and Pfizer, is a representative non-heme-binding IDO1 inhibitor with high selectivity and excellent pharmacokinetics [59]. As shown in Fig. 8, compound 12 showed moderate potency against IDO1 $\left(\mathrm{IC}_{50}=3.0 \mu \mathrm{M}\right)$, while showing no activity against IDO2 or TDO $\left(\mathrm{IC}_{50}>200 \mu \mathrm{M}\right)$. Introducing halogens to $\mathrm{C}-5$ resulted in a significant increase in activity $\left(3, \mathrm{IC}_{50}=150 \mathrm{nM}\right)$, whereas other substitutions led to decreased potency and increased tolerance. Among two enantiomers of 3, only compound $\mathbf{1 3}$ inhibited IDO1 potently $\left(\mathrm{IC}_{50}=120 \mathrm{nM}\right)$ and exhibited good antiproliferative activity against HeLa cells $\left(\mathrm{IC}_{50}=1.0 \mu \mathrm{M}\right)$. As shown in Table 4, compound 3 exhibited a low plasma clearance in rat $(3.7 \mathrm{~mL} / \mathrm{min} / \mathrm{kg})$ and human $(0.64 \mathrm{~mL} /$ $\mathrm{min} / \mathrm{kg}$ ), and moderate plasma clearance in the dog $(24.3 \mathrm{~mL} / \mathrm{min} / \mathrm{kg})$ with a low volume of distribution in these species after intravenous dose of $1 \mathrm{mg} / \mathrm{kg}(0.639$ $\mathrm{L} / \mathrm{kg}, 0.957 \mathrm{~L} / \mathrm{kg}, 1.1 \mathrm{~L} / \mathrm{kg}$, respectively), and the $\mathrm{t}_{1 / 2}$ of 3 in rats, dogs as well as human was $2.42 \mathrm{~h}, 0.84 \mathrm{~h}, 19 \mathrm{~h}$, respectively. Oral bioavailability was $94 \%$ in rats, $64 \%$ in human but only $18.6 \%$ in dogs, the high area under the concentration-time curve (AUC) in rats and low AUC in dogs were also consistent with measured bioavailability. Therefore, based on the excellent PK profiles, the racemate 3 was selected for pre-clinical and clinical studies.

The binding mode of the 3-IDO1 complex (PDB code: 5WHR) is illustrated in Fig. 9 [59]. There was no direct interaction between 3 and the heme, despite the indole ring occupied the lipophilic pocket. The heteroatoms formed H-bonding interactions. The indole $\mathrm{NH}$ hydrogen bond to the side chain of S167, the succinimide NH interacted with the heme carboxylic acid, additional two $\mathrm{H}$-bond interactions were observed between two carbonyls and the main chain of A264 and T379. Moreover, the indole aromatic core also formed hydrophobic contacts with several aromatic residues (Y126, F163, F164). The formation of these hydrogen-bond networks and the hydrophobic interactions between the indole ring and the binding pocket significantly contribute to the activity of PF06840003.

\section{Navoximod (GDC-0919, NLG-919)}

In 1989, Sono $\mathrm{M}$ et al. [30] reported the 4-phenyl-imidazole (4-PI, 15, IC $\mathrm{IC}_{50}=48 \mu \mathrm{M}$, Fig. 10 ) as a weak noncompetitive inhibitor. The binding to the heme iron of IDO1 was subsequently confirmed by the co-crystal structure of 4-PI/IDO1 (PDB code: 2D0T). The co-crystal structure revealed some key binding modes: (1) the $N$-cyclohexyl2-aminoethanesulfonic acid (CHES, highlighted in cyan) occupied the active site entrance region and its amino group and the side chain of S263 formed hydrogen-bond interaction with heme 7-propionic acid group, respectively; (2) the $\mathrm{H}$-bonding interactions were observed between CHES molecule and F226, R231 as well as the 

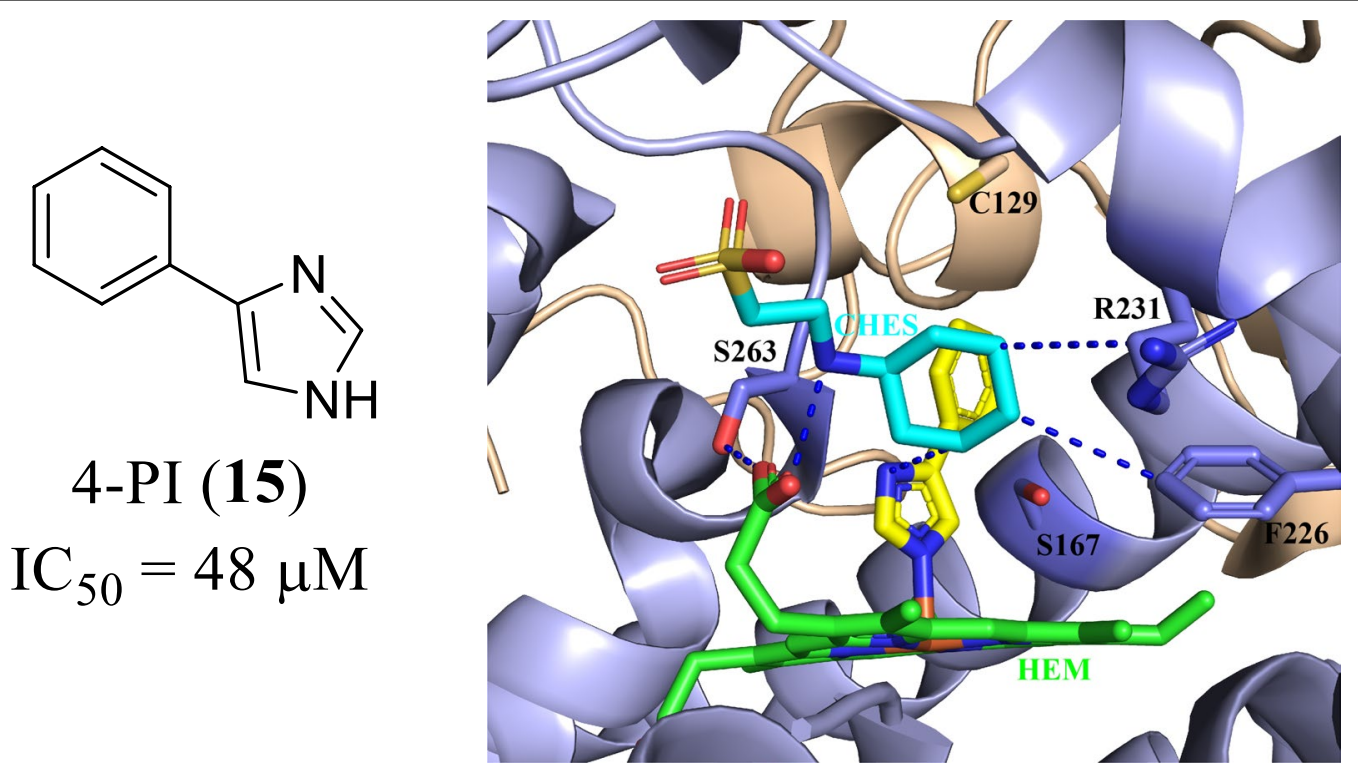

Fig. 10 The active site of the IDO1/4-PI complex (PDB code: 2D0T). The heme site is colored in green. The 4-PI is displayed in yellow stick, and the $\mathrm{CHES}$ is highlighted in cyan. The $\mathrm{H}$-bonding interactions are indicated by the blue dotted lines<smiles></smiles>

Modification of the side chain

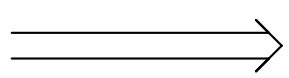

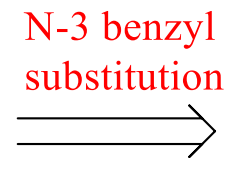<smiles>c1ccc(Cn2cncc2-c2ccccc2)cc1</smiles>
16

2' OH substitution and cyclization

$\mathrm{IC}_{50}=32 \mu \mathrm{M}$<smiles>Oc1cccc2c1-c1cncn1C2</smiles>

17<smiles>O[C@H](C[C@@H]1c2c(F)cccc2-c2cncn21)[C@H]1CC[C@H](O)CC1</smiles>

Navoximod (4) $\mathrm{IC}_{50}=28 \mathrm{nM}$

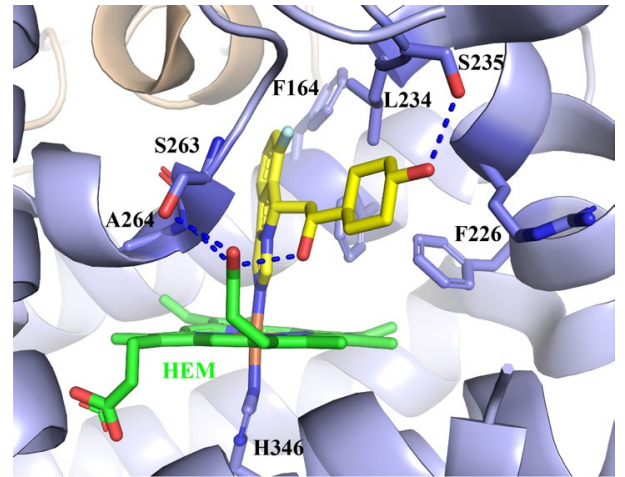

Fig. 11 The development of navoximod (PDB code: 6O3I). The heme site is colored in green. The inhibitor navoximod is displayed in yellow stick. The H-bonding interactions between Navoximod and the IDO1 protein matrix are indicated by the blue dotted lines 
Table 5 The PK profiles of navoximod

\begin{tabular}{llllll}
\hline Species & $\mathbf{C L}(\mathbf{m L} / \mathbf{m i n} /$ & $C_{\max }(\mathbf{n g} /$ & $\begin{array}{l}\boldsymbol{t}_{1 / 2} \\
\mathbf{m L})\end{array}$ & $\begin{array}{l}\boldsymbol{F} \\
(\mathbf{m})\end{array}$ & $\begin{array}{l}\text { AUC }(\mathbf{n g ~ h} / \\
\mathbf{m L})\end{array}$ \\
\hline Rat & 44.6 & 1560 & 1.44 & 41.5 & 3930 \\
Mice & 27.5 & 2257 & 3.9 & 69.0 & 6132 \\
Dog & 53.7 & 1400 & 4.8 & 22.3 & 3127 \\
\hline
\end{tabular}

$\mathrm{CL}$, Plasma clearance; $C_{\text {max }}$, peak concentration; $t_{1 / 2}$, half-life; $F$, Oral bioavailability; AUC, area under the concentration-time curve

$\mathrm{N}$-atom of the imidazole ring of 4-PI; (3) the distal heme pocket was a coordination site for the sixth external ligand (the imidazole ring).

Based on the binding interactions with IDO1, further optimization led to the discovery of a potent, orally bioavailable, and efficacious clinical candidate navoximod (NLG919, 4, Fig. 11) [89, 90]. The docking revealed that substitution on the imidazole ring of 4-PI was tolerable, and substitutions on the N-3 position of the imidazole ring would occupy the active site entrance containing a CHES buffer molecule. Compared to 14, the $N$-benzyl substituted derivative 15 showed slightly improved activity $\left(\mathrm{IC}_{50}=32 \mu \mathrm{M}\right)$. The crystal structure of 4-PI bound to IDO1 (Fig. 10) revealed that the phenyl ring was in close proximity to S167 and C129. Thus, modifications on the phenyl ring may enhance the $\mathrm{H}$-bonding interactions with S167. Researchers from the Newlink Company designed compound $17\left(\mathrm{IC}_{50}<1 \mu \mathrm{M}\right)$ through connecting $\mathrm{N}-3$ position and $2^{\prime}$ position, which occupied the active site and formed favorable proteinligand interactions. Following the tricyclic scaffold, they finally obtained another imidazoisoindole-based potent and orally bioavailable clinical candidate 4 (IDO1 $\left.\mathrm{IC}_{50}=28 \mathrm{nM}\right)$. Compound 4 eliminated IDO1-induced $\mathrm{T}$ cell suppression and restored $\mathrm{T}$ cell responses with an $\mathrm{EC}_{50}$ value of $80 \mathrm{nM}$. Regrettably, the overall response rate of navoximod combined with atezolizumab in all types of tumors was only $10 \%$. To corroborate the binding mode of navoximod, Kumar et al. [90] determined the structure of the IDO1/navoximod complex (PDB code: 6O3I, Fig. 11). The complex demonstrated that the imidazoisoindole ring of $\mathbf{4}$ coordinated with heme iron, which significantly contributed to the improved potency. And the extensive hydrophobic interactions were observed between the cyclohexane group with surrounding residues F163, F164, L234, etc. Notably, the middle hydroxy group served as an H-bonding donor to form an intramolecular hydrogen bond with the nitrogen atom of the isoindole core, which played an important role in stabilizing the conformation, enhancing the activity and improving the physicochemical properties of the compound. In addition, the terminal hydroxyl formed an H-bonding interaction with S235, and another H-bonding interaction was observed between S263 and the heme molecule. Overall, these observed interactions are responsible for the excellent inhibitory activity and selectivity of $\mathbf{4}$.

The pharmacokinetics of $\mathbf{4}$ were also studied in rats, mice and dogs following $10 \mathrm{mg} / \mathrm{kg}$ administration (Table 5). Compound 4 exhibited an $\mathrm{t}_{1 / 2}$ of $1.44 \mathrm{~h}$, $3.9 \mathrm{~h}, 4.8 \mathrm{~h}$ in rats, mice and dogs, respectively, the relevant plasma clearance was $44.6 \mathrm{~mL} / \mathrm{min} / \mathrm{kg}, 27.5 \mathrm{~mL} /$ $\mathrm{min} / \mathrm{kg}, \quad 53.7 \mathrm{~mL} / \mathrm{min} / \mathrm{kg}$, respectively. After oral

Table 6 Comparison of pharmacokinetics after a single dose of 5 or 6 in mice

\begin{tabular}{lccll}
\hline Compound & Dose $(\mu \mathrm{M} / \mathbf{k g})$ & $\boldsymbol{C}_{\max }(\boldsymbol{\mu M})$ & $\mathrm{AUC}_{\mathbf{0 - 2 4}}(\boldsymbol{\mu M} \mathbf{h})$ & $\begin{array}{l}\boldsymbol{t}_{\mathbf{1 / 2}} \\
(\mathbf{h})\end{array}$ \\
\hline Indoximod (5) & 143 & $9.3 \pm 2.2$ & $36.4 \pm 9$ & 3 \\
& 287 & $17.2 \pm 3.7$ & $77.7 \pm 21.6$ & 2.8 \\
& 573 & $26 \pm 11.1$ & $153.6 \pm 79.2$ & 3.1 \\
& 1147 & $51.7 \pm 25.4$ & $348.2 \pm 115.2$ & 3.4 \\
NLG802 (6) & 143 & $35 \pm 25.3$ & $105.4 \pm 68.5$ & 2.9 \\
& 287 & $68.9 \pm 3.9$ & $142.3 \pm 64.6$ & 2.2 \\
& 573 & $65.7 \pm 34.1$ & $150.8 \pm 76.1$ & 3.1 \\
& 1147 & $101.4 \pm 38.9$ & $374.3 \pm 180.7$ & 3.2 \\
\hline
\end{tabular}

$C_{\text {max }}$ maximum concentration observed in plasma; $\mathrm{AUC}_{0-24}$, area under the plasma concentration-time curve from 0 to $24 \mathrm{~h}$ of quantifiable concentration; $t_{1 / 2}$, half-life<smiles>CCOC(=O)[C@H](Cc1cn(C)c2ccccc12)NC(=O)[C@H](N)CC(C)C</smiles>

NLG802 (6)

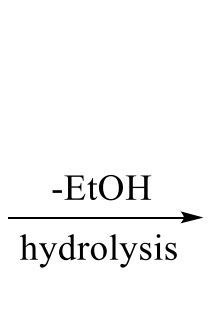<smiles>CCC</smiles><smiles>CC(C)C[C@H](N)C(=O)N[C@@H](Cc1cn(C)c2ccccc12)C(=O)O</smiles>

18<smiles>Cn1cc(C[C@H](N)C(=O)O)c2ccccc21</smiles>

Indoximod (5)

Fig. 12 Metabolic transformations of NLG802 in human hepatocytes 
administration of $50 \mathrm{mg} / \mathrm{kg}$ for $1 \mathrm{~h}$, the concentration of compound 4 in plasma $(1560 \mathrm{ng} / \mathrm{mL}$ in rats, $2257 \mathrm{ng} /$ $\mathrm{mL}$ in mice, $1400 \mathrm{ng} / \mathrm{mL}$ in dogs) was higher than that in other organs. In mice, compound 4 showed a higher bioavailability of $69 \%$ than that in rats (41.5\%) and dogs (22.3\%), the results were also consistent with measured AUC value of $6132 \mathrm{ng} \mathrm{h} / \mathrm{mL}$ (only $3930 \mathrm{ng} \mathrm{h} / \mathrm{mL}$ in rats and $3127 \mathrm{ng} \mathrm{h} / \mathrm{mL}$ in dogs). In short, compound $4 \mathrm{had}$ a favorable drug-like profile as a clinical candidate.

\section{The effector inhibitor indoximod (1-methyl-D-tryptophan, $1 \mathrm{MT}, \mathrm{NLG}-8189$ ) and its prodrug NLG802}

Trp, the endogenous ligand, had a weak inhibitory activity against IDO1 [91]. $D L-1 \mathrm{MT}$ is the first reported IDO1 inhibitor $\left(K_{i}=34 \mu \mathrm{M}\right)$ as the Trp mimetic. After chiral resolution, $L-1 \mathrm{MT}$ showed a weak inhibitory activity $\left(K_{i}=19 \mu \mathrm{M}\right)$, but $D$-1MT (indoximod, 5) did not (Fig. 12). Intriguingly, compound $\mathbf{5}$ had better antitumor activity in combination with chemotherapy drugs [92]. It is generally believed that $\mathbf{5}$ can regulate the transmembrane transport of Trp and modulate the downstream signaling pathway of IDO1 as an IDO1 bypass inhibitor. In addition, $\mathbf{5}$ could also up-regulate the co-regulatory receptor inducible co-stimulator (ICOS) of effector $\mathrm{T}$ cells as the Trp mimetic and exert an additional immunomodulatory effect.

Additionally, indoximod had a linear PK profile below $1200 \mathrm{mg} /$ dose while increasing doses above $1200 \mathrm{mg} /$ dose would cause a non-linear increase in exposure, which meant that higher concentrations of indoximod would be required to expand the pharmacodynamic effects due to the limited bioavailability. Therefore, Mautino et al. [72] synthesized a series of indoximod prodrugs including NLG802 (6) and assessed their pharmacokinetics in rats as well as in cynomolgus monkeys. As shown in Fig. 12, NLG802 was preliminarily metabolized to the intermediate 18 via hydrolysis, which was then converted to Leu and indoximod. In mice models, compared with the equivalent oral dose of $\mathbf{5}$, the maximum concentration $\left(C_{\max }\right)$ of 6 increased by a factor of $2-4$ in the range of $143-1147 \mu \mathrm{M} / \mathrm{kg}$ (Table 6), and observed daily exposure $\left(\mathrm{AUC}_{0-24}\right)$ of $\mathbf{6}$ also increased 2 and threefold at 287 and $143 \mu \mathrm{M} / \mathrm{kg}$, respectively, but the values became comparable above $573 \mu \mathrm{M} / \mathrm{kg}$, which suggested that there was a certain saturation in PK at high dose level. In general, 6 was rapidly absorbed and metabolized into indoxi$\bmod$ in vivo $\left(t_{1 / 2}=2.2-3.2 \mathrm{~h}\right)$. Furthermore, the toxicity studies revealed no adverse effect level (NOAEL) with $120 \mathrm{mg} / \mathrm{kg} /$ dose bid, which was equivalent to $3200 \mathrm{mg} /$ $\mathrm{kg} /$ dose bid in human. In conclusion, the prodrug 6 increased drug exposure and could bring additional therapeutic benefits to patients.

\section{Other clinical inhibitors}

In 2018, Dorsey et al. [93] discovered the indoline derivative LY3381916 (7) as a selective and potent inhibitor of IDO1 $\left(\right.$ IDO1 $\mathrm{IC}_{50}=7 \mathrm{nM}$, IDO2 $\left.\mathrm{IC}_{50}>20 \mu \mathrm{M}\right)$. They identified that 7 bonds to synthesized apo-IDO1 lacking heme, whereas 7 did not inhibit mature heme-bound IDO1, the novel mechanism suggests that the inhibition effect of IDO1 in tumors required the turn-over of mature heme-bound IDO1. LY3381916 has been studied in phase I clinical trial since 2017, and its therapeutic effect could be strengthened when combined with PD-L1 inhibitors, but this trial (NCT03343613) was terminated in 2020. Additionally, LY3381916 is safely administered as monotherapy, the recommended dose for combination with PD-L1 in expansion cohorts is $240 \mathrm{mg}$ (QD). In addition to the aforementioned inhibitors, other small molecules IDO1 inhibitors, including SHR9146 (the dual IDO/TDO inhibitor, NCT03208959), KHK2455 (NCT03364049) and IO102 (NCT04445064), are also at different stages of clinical trials. The chemical structures of these inhibitors and related data have been undisclosed.

\section{Conclusions and perspectives}

Cancer immunotherapy has been recognized as an effective strategy to eliminate tumor cells. IDO1 plays a pivotal role in catalyzing the Trp-Kyn pathway, and its overexpression in multiple tumor types is believed to result in either complete or local suppression of the immune system via depleting local Trp storage and accumulating downstream metabolites. Thus, IDO1 has been recognized as an attractive immunomodulatory target. Consequently, multiple IDO1-targeting therapeutic options (e.g., inhibitors, peptide vaccines, combination with anti-PD1 antibody, PROTACs) for various cancers are currently under development.

On the basis of structural features of IDO1, many small-molecule inhibitors that could coordinate with the heme iron and occupy both the hydrophobic "Pocket $A$ " and the extended conserved "Pocket B" have been developed, these structural features may provide basis for further structure-based design of IDO1 inhibitors. To date, some IDO1 inhibitors have entered clinical trials for treating various solid tumors. IDO1 inhibitors in combination with the anti-PD1 antibody have also displayed better cooperativity, which could overcome drug resistance and maximize survival benefits of patients. However, the failure of phase III study of epacadostat is the key turning point in the development of IDO1 inhibitors, it not only dismayed the research community but prompted several pharmaceutical companies to suspend or terminate relevant ongoing trials. Therefore, insights 
into the IDO1 inhibition mechanism and rational trial design may be a priority in IDO1-targeting small-molecule drug discovery.

The proteolysis-targeting chimeras (PROTACs) is an emerging strategy to degrade oncogenic proteins via the ubiquitin-proteasome pathway, a few of PROTACs molecules have been reported, and some of them have advanced into clinical trials, showing promise for cancer therapy [94-97]. To date, the first PROTAC-based IDO1 degrader has been reported [27], which conjugates the IDO1 inhibitor epacadostat to the CRBN ligand lenalidomide through a hydrophilic linker. The degrader showed effective degradation of IDO1 $\left(D_{\max }=93 \%\right.$, $\left.\mathrm{DC}_{50}=2.84 \mu \mathrm{M}\right)$ in HeLa cells and improved inhibitory activity against HER2 CAR-T cells. The discovery of this IDO1 degrader shows a novel therapeutic option, albeit with moderate degradation potency, more potent IDO1 degraders will be developed in the near future and may find clinical applications in the clinic.

Although significant progress has been made so far, some issues still exist, including: (1) the activation of AhR by IDO1 inhibitors could induce pro-carcinogenic effects in several human cancers and may be associated with poor prognosis, but it remains unknown whether the prolonged AhR activation affects cancer progression; (2) IDO1 inhibitors could mimic Trp as fake nutritional signals and reactivate the mTOR activity inhibited by Trp depletion, which may cause artificial antitumor efficacy of these inhibitors. Notably, the activation of mTOR is also capable of reactivating the T-cell function and may contribute to overcome the tumor immune escape; (3) It is worth considering whether patient populations in trials need to be stratified according to the expression level of IDO1; and (4) Due to the potential compensatory mechanism of Trp involving IDO2 or TDO, the IDO/TDO dual inhibition may be regarded as an improved approach for inhibiting the Trp-Kyn pathway. Hence, an in-depth understanding of the roles of IDO1 in cancer immunology and the search for novel IDO1 inhibitors as well as alternative targeted IDO1 therapies are still needed.

\footnotetext{
Abbreviations

AhR: Aryl hydrocarbon receptor; APCs: Antigen-presenting cells; Bin 1: Bridging integrator 1; COX-2: Cyclooxygenase; CHES: The N-cyclohexyl-2-aminoethanesulfonic acid; CTD: C-terminal domain; DAMPs: Damage-associated molecular patterns; DCs: Dendritic cells; DEL: DNA-encoded library; ECs: Endothelial cells; GCN2: General control over nonderepressible 2; GITRL: Glucocorticoidinduced TNF receptor-ralated protein; hIDO1: Human IDO1; HEM: The heme site; HTS: High throughput screening; ICOS: Inducible co-stimulator; IDO1: Indoleamine-2,3-dioxygenase-1; IL: Interleukin; IFN: Interferon; IFNR: IFN receptor; IRF1: IFN regulatory factor 1; ISRES: IFN- $\gamma$ stimulated response elements; ISX: Intestine-specfic homeobox; JAK: Janus kinase; KP: Kynurenine pathway; Kyn: Kynurenine; mTOR: The mammalian target of rapamycin; NAD ${ }^{+}$: Nicotinamide adenine dinucleotide; NKs: Natural killer cells; NPs: Natural products; NTD: N-terminal domain: PAMPs: Pathogen-associated molecular patterns: PEG: Polyethylene glycol; PGE2: Prostaglandin E2; PGER: PGE2 receptor; PI3K:
}

Phosphoinositide 3-Kinase; PKC 8 : Protein kinase C 8; PROTAC: Proteolysis targeting chimera; SAR: Structure-activity relationship; SBDD: Structure-based drug design; STAT: Transducer and activator of transcription; TAAs: Tumor-associated antigens; TDO: Tryptophan 2,3-dioxygenase; $T_{\text {eff: }}$ Effector $T$ cells; TGC

:Tumor growth control; TGF: Transforming growth factor; TGFR: TGF receptor; TLR: Toll-like receptor; TMB: Tumor mutation burden; TNF-a: Tumor necrosis factor a; Tregs: Regulatory T cells; Trp: Tryptophan; UPS: Ubiquitin/proteasome system; 4-PI: 4-Phenylimidazole.

\section{Acknowledgements \\ Not applicable.}

\section{Authors' contributions}

The authors contributed to the data preparation and drafted and revised the manuscript. All authors read and approved the final manuscript.

\section{Funding}

This work was supported by the National Natural Science Foundation of China (Nos. 81973177, 31900875 and 81703326), Program for Science \& Technology Innovation Talents in Universities of Henan Province (No. 21HASTIT045), China Postdoctoral Science Foundation (Nos. 2018M630840, 2019M662518 and 2019T120641), the Open Project of State Key Laboratory of Natural Medicines (No. SKLNMKF202005).

Availability of data and materials

Not applicable.

\section{Declarations}

Ethics approval and consent to participate

Not applicable.

\section{Consent for publication}

We declared that this manuscript is original, has not been published before, and is not currently being considered for publication elsewhere.

\section{Competing interests}

The authors declare that they have no competing interests.

\section{Author details}

${ }^{1}$ School of Pharmaceutical Sciences and Key Laboratory of Advanced Drug Preparation Technologies, Ministry of Education, Zhengzhou University, Zhengzhou 450001, China. ${ }^{2}$ School of Life Sciences, Zhengzhou University, Zhengzhou 450001, China. ${ }^{3}$ State Key Laboratory of Natural Medicines, China Pharmaceutical University, Nanjing 210009, China.

Received: 13 January 2021 Accepted: 14 April 2021

Published online: 21 April 2021

\section{References}

1. Chen DS, Mellman I. Oncology meets immunology: the cancer-immunity cycle. Immunity. 2013;39:1-10.

2. Coleman MF, Cozzo AJ, Pfeil AJ, Etigunta SK, Hursting SD. Cell intrinsic and systemic metabolism in tumor immunity and immunotherapy. Cancers. 2020;12:852

3. Emens LA, Ascierto PA, Darcy PK, Demaria S, Eggermont AMM, Redmond WL, et al. Cancer immunotherapy: opportunities and challenges in the rapidly evolving clinical landscape. Eur J Cancer. 2017;81:116-29.

4. Loo K, Tsai KK, Mahuron K, Liu J, Pauli ML, Sandoval PM, et al. Partially exhausted tumor-infiltrating lymphocytes predict response to combination immunotherapy. JCI Insight. 2017;2:e93433.

5. Piechutta M, Berghoff AS. New emerging targets in cancer immunotherapy: the role of Cluster of Differentiation 40 (CD40/TNFR5). ESMO Open. 2019;4:e000510.

6. Sharma P, Allison JP. Immune checkpoint targeting in cancer therapy: toward combination strategies with curative potential. Cell. 2015;161:205-14. 
7. Weiner LM, Dhodapkar MV, Ferrone S. Monoclonal antibodies for cancer immunotherapy. Lancet. 2009;373:1033-40.

8. Tokuyasu TA, Huang JD. A primer on recent developments in cancer immunotherapy, with a focus on neoantigen vaccines. J Cancer Metastasis Treat. 2018:4:2.

9. Holmgaard RB, Zamarin D, Munn DH, Wolchok JD, Allison JP. Indoleamine 2,3-dioxygenase is a critical resistance mechanism in antitumor T cell immunotherapy targeting CTLA-4. J Exp Med. 2013;210:1389-402.

10. Spranger S, Koblish HK, Horton B, Scherle PA, Newton R, Gajewski TF. Mechanism of tumor rejection with doublets of CTLA-4, PD-1/PD-L1, or IDO blockade involves restored IL-2 production and proliferation of $\mathrm{CD} 8(+) \mathrm{T}$ cells directly within the tumor microenvironment. J Immunother Cancer. 2014;18:3.

11. Crunkhorn S. Genentech dives deeper into the next wave of cancer immunotherapies. Nat Rev Drug Discov. 2014;13:879.

12. Stone TW, Stoy N, Darlington LG. An expanding range of targets for kynurenine metabolites of tryptophan. Trends Pharmacol Sci. 2013:34:136-43

13. Fatokun A, Hunt N, Ball H. Indoleamine 2,3-dioxygenase 2 (IDO2) and thekynurenine pathway: characteristics and potential roles in health and disease. Amino Acids. 2013;45:1319-29.

14. Platten M, von Knebel DN, Oezen I, Wick W, Ochs K. Cancer immunotherapy by targeting IDO1/TDO and their downstream effectors. Front Immunol. 2015;5:673.

15. Munn DH, Mellor AL. Indoleamine 2,3 dioxygenase and metabolic control of immune responses. Trends Immunol. 2013;34:137-43.

16. Barth H, Raghuraman S. Persistent infectious diseases say-IDO. Role of indoleamine-2,3-dioxygenase in disease pathogenesis and implications for therapy. Crit Rev Microbiol. 2014;40:360-8.

17. Platten M, Wick W, Van den Eynde BJ. Tryptophan catabolism in cancer: beyond IDO and tryptophan depletion. Cancer Res. 2012;72:5435-40.

18. Yeung AW, Terentis AC, King NJ, Thomas SR. Role of indoleamine 2,3-dioxygenase in health and disease. Clin Sci. 2015;129:601-72.

19. Kolawole AO, Hixon BP, Dameron LS, Chrisman IM, Smirnov VV. Catalytic activity of human indoleamine 2,3-dioxygenase (hIDO1) at low oxygen. Arch Biochem Biophys. 2015;15:47-57.

20. Badawy AA. Kynurenine pathway of tryptophan metabolism: regulatory and functional aspects. Int J Tryptophan Res. 2017;10:1178646917691938.

21. Ball HJ, Sanchez-Perez A, Weiser S, Austin CJD, Astelbauer F, Miu J, et al. Characterization of an indoleamine 2,3-dioxygenase-like protein found in humans and mice. Gene. 2007;396:203-13.

22. Long GV, Dummer R, Hamid O, Gajewski T, Caglevic C, Dalle S, et al. Epacadostat (E) plus pembrolizumab (P) versus pembrolizumab alone in patients (pts) with unresectable or metastatic melanoma: results of the phase 3 ECHO-301/KEYNOTE-252 study. J Clin Oncol. 2018;36:3223-30.

23. Luke JJ, Tabernero J, Joshua A, Desai J, Varga Al, Moreno V, et al. BMS986205, an indoleamine 2, 3-dioxygenase 1 inhibitor (IDO1i), in combination with nivolumab (nivo): updated safety across all tumor cohorts and efficacy in advanced bladder cancer (advBC). J Clin Oncol. 2019;37:358.

24. Nayak A, Hao Z, Sadek R, Vahanian N, Ramsey WJ, Kennedy E, et al. A Phase I study of NLG919 for adult patients with recurrent advanced solid tumors. J Immunother Cancer. 2014;2:250.

25. Qian F, Villella J, Wallace PK, Mhawech-Fauceglia P, Tario JD Jr, Andrews C, et al. Efficacy of levo-1-methyl tryptophan and dextro-1-methyl tryptophan in reversing indoleamine-2,3-dioxygenase-mediated arrest of T-cell proliferation in human epithelial ovarian cancer. Cancer Res. 2009;69:5498-504.

26. Tumang J, Gomes B, Wythes M, Crosignani S, Bingham P, Bottemanne P, et al. PF-06840003: a highly selective IDO-1 inhibitor that shows good in vivo efficacy in combination with immune checkpoint inhibitors. Cancer Res. 2016;76:abstract nr 4863.

27. Hu MX, Zhou WL, Wang YJ, Yao DP, Ye TH, Yao YQ, et al. Discovery of the first potent proteolysis targeting chimera (PROTAC) degrader of indoleamine 2,3-dioxygenase 1. Acta Pharm Sin B. 2020;10:1943-53.

28. Ye ZX, Yue LX, Shi JC, Shao MM, WU T. Role of IDO and TDO in cancers and related diseases and the therapeutic implications. J Cancer. 2019;10:2771-82.

29. Dey M, Chang AL, Miska J, Lesniak MS. The role of regulatory T cells and indoleamine-2,3-dioxygenase in brain tumor immunosuppression. In: Translational immunotherapy of brain tumors. Elsevier Inc. 2017;33-61.
30. Tomek P, Palmer BD, Flanagan JU, Sun C, Raven EL, Ching LM. Discovery and evaluation of inhibitors to the immunosuppressive enzyme indoleamine 2,3-dioxygenase 1 (IDO1): probing the active site-inhibitor interactions. Eur J Med Chem. 2017;126:983-96.

31. Hornyák L, Dobos N, Koncz G, Karányi Z, Páll D, Szabó Z, et al. The role of indoleamine-2,3-dioxygenase in cancer development, diagnostics, and therapy. Front Immunol. 2018;9:151.

32. Zhai L, Ladomersky E, Lenzen A, Nguyen B, Patel R, Lauing KL, et al. IDO1 in cancer: a Gemini of immune checkpoints. Cell Mol Immunol. 2018;15:447-57.

33. Chen B, Alvarado DM, Iticovici M, Kau NS, Park H, Parikh PJ, et al. Interferon-induced IDO1 mediates radiation resistance and is a therapeutic target in colorectal cancer. Cancer Immunol Res. 2020;8:451-64.

34. Vacchelli E, Aranda F, Eggermont A, Fridman CS, Tartour E, Eugene P, et al. Trial watch: IDO inhibitors in cancer therapy. Oncoimmunology. 2014;3:e957994.

35. Kozuma Y, Takada K, Toyokawa G, Kohashi K, Shimokawa M, Hirai F, et al. Indoleamine 2,3-dioxygenase 1 and programmed cell death-ligand 1 coexpression correlates with aggressive features in lung adenocarcinoma. Eur J Cancer. 2018;101:20-9.

36. Bezu L, Keep O, Cerrato G, Pol J, Fucikova J, Spisek R, et al. Trial watch: peptide-based anticancer vaccines. Oncoimmunology. 2015;4:e974411.

37. Werfel TA, Elion DL, Rahman B, Hicks DJ, Sanchez V, Gonzales-Ericsson PI, et al. Treatment-induced tumor cell apoptosis and secondary necrosis drive tumor progression in the residual tumor microenvironment through MerTK and IDO1. Cancer Res. 2019;79:171-82.

38. Schmidt SV, Schultze JL. New insights into IDO biology in bacterial and viral infections. Front Immunol. 2014;5:384.

39. Carbotti G, Barisione G, Airoldi I, Mezzanzanica D, Bagnoli M, Ferrero S, et al. IL-27 induces the expression of IDO and PD-L1 in human cancer cells. Oncotarget. 2015;6:43267-80.

40. Zhai LJ, Ladomersky E, Lauing KL, Wu MJ, Genet M, Gritsina G, et al. Infiltrating T cells increase IDO1 expression in glioblastoma and contribute to decreased patient aurvival. Clin Cancer Res. 2017;23:6650-60.

41. Liu YY, Liang XY, Yin XN, Lv JD, Tang K, Ma JW, et al. Blockade of IDOkynurenine-AhR metabolic circuitry abrogates IFN- - -induced immunologic dormancy of tumor-repopulating cells. Nat Commun. 2017:8:15207.

42. Blache CA, Manuel ER, Kaltcheva TI, Wong AN, Joshua DI, Ellenhorn AN, et al. Systemic delivery of Salmonella typhimurium transformed with IDO shRNA enhances intratumoral vector colonization and suppresses tumor growth. Cancer Res. 2012;72:6447-56.

43. Wei LJ, Zhu SS, Li MH, Li FX, Wei F, Liu JT, et al. High indoleamine 2,3-dioxygenase is correlated with microvessel density and worse prognosis in breast cancer. Front Immunol. 2018;9:724.

44. Zhai L, Spranger S, Binder DC, Gritsina G, Lauing KL, Giles FJ, et al. Molecular pathways: targeting IDO1 and other tryptophan dioxygenases for cancer immunotherapy. Clin Cancer Res. 2015;21:5427-33.

45. Bishnupuri KS, Alvarado DM, Khouri AN, Shabsovich M, Chen BS, Dieckgraefe BK. IDO1 and Kynurenine pathway metabolites activate PI3K-Akt signaling in the neoplastic colon epithelium to promote cancer cell proliferation and inhibit apoptosis. Cancer Res. 2019;79:1138-50.

46. Liu M, Wang X, Wang L, Ma XD, Gong ZJ, Zhang SS, et al. Targeting the IDO1 pathway in cancer: from bench to bedside. J Hematol Oncol. 2018:11:100.

47. Wang LT, Chiou SS, Chai CY, His E, Yokoyama KK, Wang SN, et al. Intestinespecific homeobox gene ISX integrates IL6 signaling, tryptophan catabolism, and immune suppression. Cancer Res. 2017;77:4065-77.

48. Murray IA, Patterson AD, Perdew GH. Aryl hydrocarbon receptor ligands in cancer: friend and foe. Nat Rev Cancer. 2014;14:801-14.

49. Crosignani S, Bingham P, Bottemanne P, Cannelle H, Cauwenberghs S, Cordonnier $\mathrm{M}$, et al. Discovery of a novel and selective indoleamine 2,3-dioxygenase (IDO-1) inhibitor 3-(5-fluoro-1 H-indol-3-yl)pyrrolidine2,5-dione (EOS200271/PF-06840003) and its characterization as a potential clinical candidate. J Med Chem. 2017;60:9617-29.

50. Liu YY, Liang XY, Dong WQ, Fang Y, Lv JD, Zhang TZ, et al. Tumor-repopulating cells induce PD-1 expression in CD8+ T cells by transferring kynurenine and AhR activation. Cancer Cell. 2018;33:480-94.

51. Cheong JE, Sun L. Targeting the IDO1/TDO2-KYN-AhR pathway for cancer immunotherapy-challenges and opportunities. Trends Pharmacol Sci. 2018;39:307-25. 
52. Röhrig UF, Awad L, Grosdidier A, Larrieu P, Stroobant V, Colau D, et al. Rational design of indoleamine 2,3-dioxygenase inhibitors. J Med Chem. 2010:53:1172-89.

53. Lewis-Ballester A, Pham KN, Batabyal D, Karkashon S, Bonanno JB, Poulos $\mathrm{TL}$, et al. Structural insights into substrate and inhibitor binding sites in human indoleamine 2,3-dioxygenase 1. Nat Commun. 2017:8:1693.

54. Sugimoto H, Oda S, Otsuki T, Hino T, Yoshida T, Shiro Y. Crystal structure of human indoleamine 2,3 dioxygenase: catalytic mechanism of $\mathrm{O} 2$ incorporation by a heme-containing dioxygenase. Proc Natl Acad Sci USA. 2006;103:2611-6.

55. Littlejohn TK, Takikawa O, Truscott RJ, Walker MJ. Asp274 and his346 are essential for heme binding and catalytic function of human indoleamine 2,3-dioxygenase. J Biol Chem. 2003;278:29525-31.

56. Rohrig UF, Reynaud A, Majjigapu SR, Vogel P, Pojer F, Zoete V. Inhibition mechanisms of indoleamine 2,3-dioxygenase 1 (IDO1). J Med Chem. 2019;62:8784-95.

57. Rohrig UF, Majjigapu SR, Vogel P, Zoete V, Michielin O. Challenges in the discovery of indoleamine 2,3-dioxygenase 1 (IDO1) Inhibitors. J Med Chem. 2015;58:9421-37.

58. Zhang Y, Kang SA, Mukherjee T, Bale S, Crane BR, Begley TP, et al. Crystal structure and mechanism of tryptophan 2,3-dioxygenase, a heme enzyme involved in tryptophan catabolism and in quinolinate biosynthesis. Biochemistry. 2007;46:145-55.

59. Luo SK, Xu K, Xiang SY, Chen J, Chen CY, Guo CX, et al. High-resolution structures of inhibitor complexes of human indoleamine 2,3-dioxygenase 1 in a new crystal form. Acta Crystallogr F Struct Biol Commun. 2018;74:717-24

60. Serafini M, Torre E, Aprile S, Grosso ED, Gesu A, Griglio A, et al. Discovery of highly potent benzimidazole derivatives as indoleamine 2,3-dioxygenase-1 (IDO1) inhibitors: from structure-based virtual screening to in vivo pharmacodynamic activity. J Med Chem. 2020;63:3047-65.

61. Griglio A, Torre E, Serafini M, Bianchi A, Schmid R, Coda ZG. A multicomponent approach in the discovery of indoleamine 2,3-dioxygenase 1 inhibitors: synthesis, biological investigation and docking studies. Bioorg Med Chem Lett. 2018;28:651-7.

62. Liu M, Wang X, Wang L, Ma X, Gong Z, Zhang S, et al. Targeting the IDO1 pathway in cancer: from bench to bedside. J Hematol Oncol. 2018;11:100.

63. Long GV, Dummer R, Hamid O, Gajewski TF, Caglevic C, Dalle S, et al. Epacadostat plus pembrolizumab versus placebo plus pembrolizumab in patients with unresectable or metastatic melanoma (ECHO-301/ KEYNOTE-252): a phase 3, randomised, double-blind study. Lancet Oncol. 2019:20:1083-97.

64. Sonpavde G, Necchi A, Gupta S, Steinberg GD, Gschwend JE, Van Der Heijden MS, et al. ENERGIZE: a Phase III study of neoadjuvant chemotherapy alone or with nivolumab with/without linrodostat mesylate for muscle-invasive bladder cancer. Future Oncol. 2020;16:4359-68.

65. Nayak-Kapoor A, Hao ZL, Sadek R, Dobbins R, Marshall L, Vahanian NN, et al. Phase la study of the indoleamine 2,3-dioxygenase 1 (IDO1) inhibitor navoximod (GDC-0919) in patients with recurrent advanced solid tumors. J Immunother Cancer. 2018;6:61.

66. Jung KH, LoRusso P, Burris H, Gordon M, Bang YJ, Hellmann MD, et al. Phase I study of the indoleamine 2,3-dioxygenase 1 (IDO1) inhibitor Navoximod (GDC-0919) administered with PD-L1 inhibitor (Atezolizumab) in advanced solid tumors. Clin Cancer Res. 2019;25:3220-8.

67. Reardon DA, Desjardins A, Rixe O, Cloughesy T, Alekar S, Williams JH, et al. A phase 1 study of PF-06840003, an oral indoleamine 2,3-dioxygenase 1 (IDO1) inhibitor in patients with recurrent malignant glioma. Invest New Drugs. 2020;6:1784-95.

68. Gomes B, Driessens G, Bartlett D, Cloughesy T, Alekar S, Williams JH, et al. Characterization of the selective indoleamine 2,3-dioxygenase-1 (IDO1) catalytic inhibitor EOS200271/PF-06840003 supports IDO1 as a critical resistance mechanism to PD-(L)1 blockade therapy. Mol Cancer Ther. 2018;17:2530-42.

69. Fox E, Oliver T, Rowe M, Thomas S, Zakharia Y, Gilman PB, et al. Indoximod: an immunometabolic adjuvant that empowers $T$ cell activity in cancer. Front Oncol. 2018:8:370

70. Metz R, Rust S, Duhadaway JB, Mautino MR, Munn DH, Vahanian NN, et al. IDO inhibits a tryptophan sufficiency signal that stimulates mTOR: a nove IDO effector pathway targeted by D-1-methyl-tryptophan. Oncoimmunology. 2012;1:1460-8.
71. Brincks EL, Adams J, Wang LF, Turner B, Marcinowicz A, Ke JY, et al. Indoximod opposes the immunosuppressive effects mediated by IDO and TDO via modulation of AhR function and activation of mTORC1. Oncotarget. 2020;11:2438-61.

72. Kumar S, Jaipuri FA, Waldo JP, Potturi H, Marcinowicz A, Adams J, et al. Discovery of indoximod prodrugs and characterization of clinical candidate NLG802. Eur J Med Chem. 2020;198:112373.

73. Soliman H, Khambati F, Han HS, Ismail-Khan R, Bui MM, Sullivan DM, et al. A phase-1/2 study of adenovirus-p53 transduced dendritic cell vaccine in combination with Indoximod in metastatic solid tumors and invasive breast cancer. Oncotarget. 2018;9:10110-7.

74. Dhiman V, Giri KK, Suresh PS, Zainuddin M, Rajagopal S, Mullangi R. Determination of epacadostat, a novel IDO1 inhibitor in mouse plasma by LC-MS/MS and its application to a pharmacokinetic study in mice. Biomed Chromatogr. 2017;31:e3794.

75. Jochems C, Fantini M, Fernando RI, Kwilas AR, Donahue RN, Lepone LM, et al. The IDO1 selective inhibitor epacadostat enhances dendritic cell immunogenicity and lytic ability of tumor antigen-specific T cells. Oncotarget. 2016;7:37762-72.

76. Gibney GT, Hamid O, Lutzky J, Olszanski AJ, Mitchell TC, Gajewski TF, et al. Phase $1 / 2$ study of epacadostat in combination with ipilimumab in patients with unresectable or metastatic melanoma. J Immunother Cancer. 2019;7:80.

77. Epacadostat shows value in two SCCHN trials. Cancer Discov. 2017;7:OF2.

78. Blocking IDO1 helps shrink bladder, cervical tumors. Cancer Discov. 2018:8:OF3.

79. Cheong JE, Ekkati A, Sun LJ. A patent review of IDO1 inhibitors for cancer. Expert Opin Ther Pat. 2018;28:317-30.

80. Andersen $\mathrm{MH}$, Svane IM. Indoleamine 2,3-dioxygenase vaccination. Oncoimmunology. 2015;4:e983770.

81. Iversen TZ, Engell-Noerregaard L, Ellebaek E, Andersen R, Larsen SK, Bjoern J, et al. Long-lasting disease stabilization in the absence of toxicity in metastatic lung cancer patients vaccinated with an epitope derived from indoleamine 2,3 dioxygenase. Clin Cancer Res. 2014;20:221-32.

82. Bjoern J, Iversen TZ, Nitschke NJ, Andersen MH, Svane IM. Safety, immune and clinical responses in metastatic melanoma patients vaccinated with a long peptide derived from indoleamine 2,3-dioxygenase in combination with ipilimumab. Cytotherapy. 2016;18:1043-55.

83. Souza LC, Jesse CR, Del FL, Gomes MG, Goes ATR, Filho CB, et al. Swimming exercise prevents behavioural disturbances induced by an intracerebroventricular injection of amyloid- $\beta(1-42)$ peptide through modulation of cytokine/NF-kappaB pathway and indoleamine-2,3-dioxygenase in mouse brain. Behav Brain Res. 2017;331:1-13.

84. Yue EW, Douty B, Wayland B, Bower M, Liu XD, Leffet L, et al. Discovery of potent competitive inhibitors of indoleamine 2,3-dioxygenase with in vivo pharmacodynamic activity and efficacy in a mouse melanoma model. J Med Chem. 2009;52:7364-7.

85. Yue EW, Sparks R, Polam P, Modi D, Douty B, Wayland B, et al. INCB24360 (epacadostat), a highly potent and selective indoleamine-2,3-dioxygenase 1 (IDO1) inhibitor for immuno-oncology. ACS Med Chem Lett. 2017:8:486-91.

86. Van den Eynde BJ, van Baren N, Baurain JF. Is there a clinical future for Ido1 inhibitors after the failure of epacadostat in melanoma? Annu Rev Cancer Biol. 2020;4(241-256):89.

87. Pham KN, Yeh SR. Mapping the binding trajectory of a suicide inhibitor in human indoleamine 2,3-dioxygenase 1. J Am Chem Soc. 2018;140:14538-41.

88. Nelp MT, Kates PA, Hunt JT, Newitt JA, Balog A, Maley D, et al. Immunemodulating enzyme indoleamine 2,3-dioxygenase is effectively inhibited by targeting its apo-form. Proc Natl Acad Sci U S A. 2018;115:3249-54.

89. Mario RM, Firoz AJ, Jesse W, Kumar S, Adams J, Allen CV, et al. NLG919, a novel indoleamine-2,3-dioxygenase (IDO)-pathway inhibitor drug candidate for cancer therapy. Cancer Res. 2013;73:491.

90. Kumar S, Waldo JP, Jaipuri FA, Marcinowicz A, Van Allen C, Adams J, et al. Discovery of clinical candidate (1R,4r)-4-((R)-2-((S)-6-fluoro-5Himidazo[5,1-a]isoindol-5-yl)-1-hydroxyethyl)cyc lohexan-1-ol (navoximod), a potent and selective inhibitor of indoleamine 2,3-dioxygenase 1. J Med Chem. 2019;62:6705-33. 
91. Muller AJ, Malachowski GC, Prendergast GC. Indoleamine 2,3-dioxygenase in cancer: targeting pathological immune tolerance with smallmolecule inhibitors. Expert Opin Ther Targets. 2005;9:831-49.

92. Fu TH, He QM, Sharma P. The ICOS/ICOSL pathway is required for optimal antitumor responses mediated by anti-CTLA-4 therapy. Cancer Res. 2011;71:5445-54.

93. Frank $C D$, Karim AB, Lillian LS. Identification and characterization of the IDO1 inhibitor LY3381916. Cancer Res. 2018;78:5245.

94. Hu B, Zhou Y, Sun D, Yang Y, Liu Y, Li X, et al. PROTACs: new method to degrade transcription regulating proteins. Eur J Med Chem. 2020;207:112698.

95. Martín-Acosta P, Xiao X. PROTACs to address the challenges facing small molecule inhibitors. Eur J Med Chem. 2021;210:112993.
96. Toure M Crews CM. Small-molecule PROTACS: new approaches to protein degradation. Angew Chem Int Ed Engl. 2016;55:1966-73.

97. Zeng S, Huang W, Zheng X, Ch LY, Zhang Z, Wang J, et al. Proteolysis targeting chimera (PROTAC) in drug discovery paradigm: recent progress and future challenges. Eur J Med Chem. 2021;210:112981.

\section{Publisher's Note}

Springer Nature remains neutral with regard to jurisdictional claims in published maps and institutional affiliations.
Ready to submit your research? Choose BMC and benefit from:

- fast, convenient online submission

- thorough peer review by experienced researchers in your field

- rapid publication on acceptance

- support for research data, including large and complex data types

- gold Open Access which fosters wider collaboration and increased citations

- maximum visibility for your research: over $100 \mathrm{M}$ website views per year

At BMC, research is always in progress.

Learn more biomedcentral.com/submissions 